2009s-21

\title{
Dependence Structure and Extreme Comovements in International Equity and Bond Markets
}

\author{
René Garcia, Georges Tsafack
}

Série Scientifique
Scientific Series

\author{
Montréal \\ Mai 2009
}

(C) 2009 René Garcia, Georges Tsafack. Tous droits réservés. All rights reserved. Reproduction partielle permise avec citation du document source, incluant la notice (C).

Short sections may be quoted without explicit permission, if full credit, including (C) notice, is given to the source.
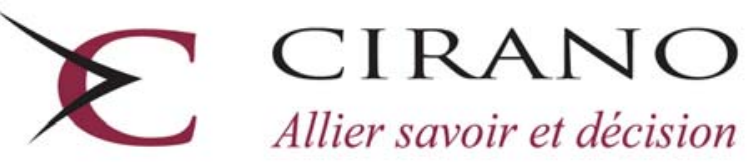

Allier savoir et décision

Centre interuniversitaire de recherche en analyse des organisations 


\section{CIRANO}

Le CIRANO est un organisme sans but lucratif constitué en vertu de la Loi des compagnies du Québec. Le financement de son infrastructure et de ses activités de recherche provient des cotisations de ses organisations-membres, d'une subvention d’infrastructure du Ministère du Développement économique et régional et de la Recherche, de même que des subventions et mandats obtenus par ses équipes de recherche.

CIRANO is a private non-profit organization incorporated under the Québec Companies Act. Its infrastructure and research activities are funded through fees paid by member organizations, an infrastructure grant from the Ministère du Développement économique et régional et de la Recherche, and grants and research mandates obtained by its research teams.

\section{Les partenaires du CIRANO}

\section{Partenaire majeur}

Ministère du Développement économique, de l’Innovation et de l’Exportation

\section{Partenaires corporatifs}

Banque de développement du Canada

Banque du Canada

Banque Laurentienne du Canada

Banque Nationale du Canada

Banque Royale du Canada

Banque Scotia

Bell Canada

BMO Groupe financier

Caisse de dépôt et placement du Québec

DMR

Fédération des caisses Desjardins du Québec

Gaz de France

Gaz Métro

Hydro-Québec

Industrie Canada

Investissements PSP

Ministère des Finances du Québec

Power Corporation du Canada

Raymond Chabot Grant Thornton

Rio Tinto Alcan

State Street Global Advisors

Transat A.T.

Ville de Montréal

\section{Partenaires universitaires}

École Polytechnique de Montréal

HEC Montréal

McGill University

Université Concordia

Université de Montréal

Université de Sherbrooke

Université du Québec

Université du Québec à Montréal

Université Laval

Le CIRANO collabore avec de nombreux centres et chaires de recherche universitaires dont on peut consulter la liste sur son site web.

Les cahiers de la série scientifique (CS) visent à rendre accessibles des résultats de recherche effectuée au CIRANO afin de susciter échanges et commentaires. Ces cahiers sont écrits dans le style des publications scientifiques. Les idées et les opinions émises sont sous l'unique responsabilité des auteurs et ne représentent pas nécessairement les positions du CIRANO ou de ses partenaires.

This paper presents research carried out at CIRANO and aims at encouraging discussion and comment. The observations and viewpoints expressed are the sole responsibility of the authors. They do not necessarily represent positions of CIRANO or its partners. 


\title{
Dependence Structure and Extreme Comovements in International Equity and Bond Markets*
}

\author{
René Garcia ${ }^{\dagger}$, Georges Tsafack ${ }^{\ddagger}$
}

\begin{abstract}
Résumé
Les écarts de rendement négatifs extrêmes communs existent dans les marchés boursiers internationaux. Ce phénomène a été largement démontré par des outils statistiques, tels que la corrélation des dépassements, la théorie des valeurs extrêmes et les modèles GARCH bivarié en langage Gauss ou avec changement de régime. Nous signalons les limites de ces outils pour caractériser la dépendance extrême et proposons un modèle de copules avec changement de régime, comprenant un régime normal dans lequel la dépendance est symétrique et un second régime caractérisé par une dépendance asymétrique. De plus, afin de saisir pleinement l'incidence potentielle de cette dépendance asymétrique en termes de diversification du portefeuille, nous appliquons ce modèle aux marchés internationaux des actions et des obligations, afin de permettre les mouvements entre les marchés. D’un point de vue empirique, nous constatons une forte dépendance entre les actifs internationaux de même type dans les deux régimes, surtout dans le régime asymétrique, et une faible dépendance entre les actions et les obligations, bien qu'il soit question d'un même pays. Nous procédons à un examen analytique afin de déterminer quand et comment la dépendance asymétrique peut, lors de la répartition du portefeuille, amplifier les phénomènes suivants établis empiriquement : fuite vers la sécurité et surinvestissement dans des sociétés proches du domicile.
\end{abstract}

Mots clés : corrélation asymétrique, dépendance asymétrique, copules, dépendance dans les queues, GARCH, changement de régime, surinvestissement dans des sociétés proches du domicile, fuite vers la sécurité.

\footnotetext{
* This paper was circulating under the title "Dependence Structure and Extreme Comovements in International Equity and Bond Markets with Portfolio Diversification Effects".

The first author is a research Fellow of CIRANO and CIREQ. He gratefully acknowledges financial support from the Bank of Canada, the Fonds de la Formation de Chercheurs et l'Aide à la Recherche du Québec (FCAR), the Social Sciences and Humanities Research Council of Canada (SSHRC), and the MITACS Network of Centres of Excellence. Financial Support by CIREQ and CIRANO is gratefully acknowledged by the second author. We thank Jean Marie Dufour, Eric Girardin, Silvia Gonçalves, Eric Jacquier, Nour Meddahi, Benoit Perron, Eric Renault, Romeo Tedongap, Per Strömberg and participants at the Financial Management Association Doctoral Consortium at Chicago, the Conference on Multivariate Models for Volatility at Algarve, the Conference on Measuring Dependence in Economics and Finance at Cass Business School, the Seminar at London School of Economics, GREQAM-Marseille, Ryerson University, Suffolk University, and Stockholm School of Economics for their constructive comments and suggestions. We are grateful to Lorenzo Cappiello, Robert Engle and Kevin Sheppard for providing us with their dataset.

† Corresponding author. Tel.: +33493187802; Fax: +33493187841; E-mail address: rene.garcia@edhec.edu Edhec Business School, 393 Promenade des Anglais, C.P. 3116, 06202, Nice, Cedex 3, France. ‡ Department of Economics, Emory University, Atlanta, GA 30322-2240, USA.
} 


\begin{abstract}
Common negative extreme variations in returns are prevalent in international equity markets. This has been widely documented with statistical tools such as exceedance correlation, extreme value theory, and Gaussian bivariate GARCH or regime-switching models. We point to limits of these tools to characterize extreme dependence and propose an alternative regime-switching copula model that includes one normal regime in which dependence is symmetric and a second regime characterized by asymmetric dependence. Moreover, to fully appreciate the potential effects of this asymmetric dependence in terms of portfolio diversification, we apply this model to international equity and bond markets, to allow for inter-market movements. Empirically, we find that dependence between international assets of the same type is strong in both regimes, especially in the asymmetric one, but weak between equities and bonds, even in the same country. We study analytically how and when asymmetric dependence may amplify empirically documented phenomena such as flight to safety and home bias in portfolio allocation.
\end{abstract}

Keywords: asymmetric correlation, asymmetric dependence, copula, tail dependence, GARCH, regime switching, home bias, flight to safety

Codes JEL : C32, C51, G15 


\section{Introduction}

There is ample evidence that negative returns are more dependent than positive returns in international equity markets. This phenomenon known as asymmetric dependence has been reported by many previous studies including Erb et al (1994), Longin and Solnik (2001), Ang and Bekaert (2002), Ang and Chen (2002), Das and Uppal (2003), Patton (2004), and references therein. This asymmetric dependence has important implications for portfolio allocation, but to appreciate its full actual effects on portfolio diversification, stocks and bonds have to be considered together, both at the domestic and international levels to allow for inter-market movements ${ }^{1}$. Models of extreme dependence in international stock and bond markets are mainly missing in the literature. This is due mainly to the fact that measuring and modeling asymmetric dependence remains a challenge.

Previous studies relied on the concept of exceedance correlation, correlation computed for returns above or below a certain threshold, to investigate the dependence structure between financial returns. ${ }^{2}$ Boyer et al (1999) and Forbes and Rigobon (2002) remark that correlations estimated conditionally on high or low returns or volatility suffer from some conditioning bias. Correlation asymmetry may therefore appear spuriously if these biases are not accounted for. To avoid these problems, Longin and Solnik (2001) use extreme value theory (EVT) by focusing on the asymptotic value of exceedance correlation ${ }^{3}$. The benefit of EVT resides in the fact that the asymptotic result holds regardless of the distribution of returns. By the same token, as emphasized by Longin and Solnik (2001), EVT cannot help to determine if a given return-generating process is able to reproduce the extreme asymmetric exceedance correlation observed in the data.

To overcome this shortcoming, we propose a model based on copulas that allows for tail dependence in lower returns and keeps tail independence for upper returns as suggested by

\footnotetext{
${ }^{1}$ Patton (2004) finds that the knowledge of asymmetric dependence leads to gains that are economically significant, while Ang and Bekaert (2002), in a regime switching setup, argue that the costs of ignoring the difference between regimes of high and low dependence are small, but increase with the possibility to invest in a risk-free asset.

${ }^{2}$ The exceedance correlation between two series of returns is defined as the correlation for a sub-sample in which the returns of both series are simultaneously lower (or greater) than the corresponding thresholds $\theta_{1}$ and $\theta_{2}$. Formally, exceedance correlation of variables $X$ and $Y$ at thresholds $\theta_{1}$ and $\theta_{2}$ is expressed by

$E x_{-} \operatorname{corr}\left(Y, X ; \theta_{1}, \theta_{2}\right)=\left\{\begin{array}{l}\operatorname{corr}\left(X, Y \mid X \leq \theta_{1}, Y \leq \theta_{2}\right), \text { for } \theta_{1} \leq 0 \text { and } \theta_{2} \leq 0 \\ \operatorname{corr}\left(X, Y \mid X \geq \theta_{1}, Y \geq \theta_{2}\right), \text { for } \theta_{1} \geq 0 \text { and } \theta_{2} \geq 0\end{array}\right.$. Longin and Solnik (2001) use $\theta_{1}=\theta_{2}=\theta$, while Ang and Chen (2002) use $\theta_{1}=(1+\theta) \bar{X}$ and $\theta_{2}=(1+\theta) \bar{Y}$, where $\bar{X}$ and $\bar{Y}$ are the means of $Y$ and $X$ respectively.

${ }^{3}$ Extreme Value Theory (EVT) is used to characterize the distribution of a variable conditionally to the fact that its values are beyond a certain threshold, and the asymptotic distribution is obtained when this threshold tends to infinity. Hartmann, Straetmans and De Vries (2004) also use extreme-value analysis to capture the dependence structure between stock and bond returns for pairs of the G5 countries.
} 
the findings of Longin and Solnik (2001). Copulas are functions that build multivariate distribution functions from their unidimensional marginal distributions ${ }^{4}$. The tail dependence coefficient can be seen as the probability of the worst event occurring in one market given that the worst event occurs in another market. Contrary to exceedance correlation, the estimation of the tail dependence coefficient is not subject to the problem of choosing an appropriate threshold and the use of extreme value distributions such as the Pareto distribution. Another difference is that tail dependence is completely defined by the dependence structure and is not affected by variations in marginal distributions.

The disentangling between marginal distributions and dependence helps overcoming the curse of dimensionality associated with the estimation of models with several variables. For example, in multivariate GARCH models, the estimation becomes intractable when the number of series being modeled is high. The CCC of Bollerslev (1990), the DCC of Engle (2002), and the RSDC of Pelletier (2004) deal with this problem by separating the variance-covariance matrix in two parts, one part for the univariate variances of the different marginal distributions, another part for the correlation coefficients. This separation allows them to estimate the model in two steps, first the marginal parameters on each individual series then the correlation parameters. Copulas offer a tool to generalize this separation while extending the linear concept of correlation to nonlinear dependence.

Thanks to the tail dependence formulation of asymptotic dependence, we show analytically that the multivariate GARCH or regime switching (RS) models with Gaussian innovations that have been used to address asymmetric dependence issues (see Ang and Bekaert, 2002, and Ang and Chen, 2002) cannot in fact reproduce extreme asymmetric dependence. The key point is that these classes of models can be seen as mixtures of symmetric distributions and cannot produce asymptotically asymmetric dependence. The asymmetry produced by these models at finite distance disappears asymptotically. When we go far in the tails, we obtain a similar dependence for the upper and lower tails. Moreover, the asymmetry in RS models comes from the asymmetry created in the marginal distributions with regime switching in the mean. Hence it is not separable from the marginal asymmetry or skewness. ${ }^{5}$ This is a fundamental issue that also affects the statistical extreme-value

\footnotetext{
${ }^{4}$ The theory of this useful tool dates back to Sklar (1959) and a clear presentation can be found in Nelsen (1999). Well designed to analyze nonlinear dependence, copulas were initially used by statisticians for nonparametric estimation and measure of dependence of random variables (see Genest and Rivest, 1993 and references therein)

${ }^{5}$ Ang and Chen (2002) conclude that even if regime-switching models perform best in explaining the amount of correlation asymmetry reflected in the data, these models still leave a significant amount of correlation asymmetry in the data unexplained.
} 
analyses that have been conducted to study extreme dependence.

We use our regime-switching copula model to investigate the dependence structure between international equity and bond markets. The model allows for a switching between a normal state where markets will be linearly and symmetrically correlated and an asymmetric dependence state to capture common crashes. In a normal regime it is difficult to make a difference between the level of dependence for joint positive moves and joint negative moves. When the economy is in the asymmetric regime, even with a stable correlation, a downside move in one market will increase the probability of a similar event in another market. The rise in the level of dependence during market downturns is characterized by asymmetry in the dependence structure. This regime can be interpreted as contagion since bad news spread quickly between markets. This crash dependence can coexist with low correlation and implies a reduction of an apparent diversification benefit. This is an essential point to consider for portfolio allocation that has not received proper attention.

We separately analyze dependence between the two leading markets in North-America (US and Canada) and two major markets of the Euro zone (France and Germany). Our empirical analysis shows that dependence between international assets of the same type is strong in both the symmetric and the asymmetric regimes, while dependence between equities and bonds is low even in the same country. Another finding is that the presence of a regime with extreme asymmetric dependence makes the correlation in the normal regime differ from the unconditional correlation. We also provide some evidence that exchange rate volatility seems to contribute to asymmetric dependence. With the introduction of a fixed exchange rate the dependence between France and Germany becomes less asymmetric and more normal than before. High exchange rate volatility is associated with a high level of asymmetry. These results are consistent with those of Cappiello, Engle and Sheppard (2003) who find an increase in correlation after the introduction of the Euro currency.

Our last contribution is to explore analytically the effects of asymmetric dependence on cross-country and domestic diversification. An analytical approach is important to better understand the mechanisms at hand behind asymmetric dependence and their impact on portfolio allocation. First, we establish a link between co-skewness and asymmetric dependence. Then we show that strong dependence in lower returns in two markets can reduce co-skewness and therefore lower skewness in a portfolio with long positions in both markets. Since the reduction of co-skewness lowers the gains to diversification, investors tend to hold a higher share of low-risk assets than in a mean-variance portfolio. In other words, asymmetric dependence increases downside risk and therefore, very risk-averse investors tend to 
switch toward less risky assets when downside dependence increases. A similar behavior is observed for the bond and equity trade-off. In the asymmetric dependence regime, the very risk-averse agent increases the fraction of its wealth in bonds. Therefore we conclude that empirical documented phenomena such as home bias and flight to safety may be amplified by asymmetric dependence.

The rest of this paper is organized as follows. Section 2 reformulates the empirical facts about exceedance correlation in terms of tail dependence and shows how classical GARCH or regime switching models fail to capture these facts. In section 3 we develop a model with two regimes that clearly disentangles dependence from marginal distributional features and allows asymmetry in extreme dependence. As a result, we obtain a model with four variables that features asymmetry and a flexible dependence structure. Empirical evidence on the dependence structure is examined in section 4, while section 5 analyzes analytically the implications of asymmetric dependence on international and domestic diversification. Conclusions are drawn in section 6.

\section{Extreme Asymmetric Dependence and Modeling Issues}

In this section we present empirical facts about exceedance correlation in international equity market returns put forward by Longin and Solnik (2001) and the related literature. We next argue that these facts can be equivalently reformulated in terms of tail dependence. The latter formulation will allow us to explain why classical return-generating processes such as GARCH and regime-switching models based on a multivariate normal distribution fail to reproduce these empirical facts.

\subsection{Empirical Facts}

Longin and Solnik (2001) investigate the structure of correlation between various equity markets in extreme situations by testing the equality of exceedance correlations, one obtained under a joint normality assumption and the other one computed using EVT. For the latter distribution, they model the marginal distributions of equity index returns with a generalized Pareto distribution (GPD) and capture dependence through a logistic function. Ang and Chen (2002) develop a test statistic based on the difference between exceedance correlations computed from the data and those obtained from GARCH or RS models ${ }^{6}$

\footnotetext{
${ }^{6}$ They define a test statistic $H=\left[\sum_{i=1}^{N} \frac{1}{N}\left(\rho\left(\vartheta_{i}\right)-\widehat{\rho}\left(\vartheta_{i}\right)\right)^{2}\right]^{1 / 2}$ which is the distance between exceedance correlations obtained from the normal distribution $\left(\rho\left(\vartheta_{1}\right), \ldots, \rho\left(\vartheta_{N}\right)\right)$ and exceedance correlations estimated from the data $\left(\widehat{\rho}\left(\vartheta_{1}\right), \ldots, \widehat{\rho}\left(\vartheta_{N}\right)\right)$ for a set of $N$ selected thresholds $\left\{\vartheta_{1}, \ldots, \vartheta_{N}\right\}$. In the same way they define
} 
These two studies conclude that there exists asymmetry in exceedance correlation, that is large negative returns are more correlated than large positive returns. However, their results rely on choosing a set of thresholds for computing exceedance correlation and can only account for asymmetry at finite distance. Crashes are more in the nature of extreme events and involve measuring dependence for thresholds very far in the tail. Longin and Solnik (2001) confirm with an asymptotic test that exceedance correlation is positive and statistically different from zero for very large negative returns and not different from zero for very large positive returns. However they do not provide a model that is able to reproduce this fact. Ang and Chen (2002) as well as Ang and Bekaert (2002) find that regime switching models can reproduce the asymmetry in exceedance correlation, but this result does not hold for extreme events as we will show later and the measured asymmetry amalgamates skewness in the marginal distributions and asymmetric dependence.

We illustrate these facts and the capacity of models to reproduce them in Figure 1 with US and Canadian returns. We specify thresholds in term of quantiles: $\theta_{1}=F_{X}^{-1}(\alpha)$ and $\theta_{2}=F_{Y}^{-1}(\alpha)$ where $F_{X}$ and $F_{Y}$ are the cumulative distribution functions of $Y$ and $X$ respectively. Following Longin and Solnik (2001) and Ang and Chen (2002) exceedance correlations are symmetric if $E x \_$corr $\left(Y, X ; \theta_{1}, \theta_{2}\right)=E x \_\operatorname{corr}\left(Y, X ; 1-\theta_{1}, 1-\theta_{2}\right) ; \alpha \in$ $(0,1)$. Correlations of return exceedances exhibit the typical shape put forward in Longin and Solnik (2001) for the US equity market with various European equity markets. For the models, we chose to retain the multivariate normal, as a benchmark case to show that correlations go to zero as we move further in the tails, as well as a normal regime switching model, as in Ang and Chen (2002). The latter model produces some asymmetry in correlations for positive and negative returns but not nearly as much as in the data. We also exhibit the exceedance correlations estimated with the procedure used by Longin and Solnik (2001). It is evidently much closer to the data. Finally, we also report the correlations obtained from a rotated Gumbel copula for the dependence function (see Appendix for a definition), with Gaussian marginal distributions. The graph is very close to the Longin and Solnik (2001) one.

Since asymptotic exceedance correlation is zero for both sides of a bivariate normal distribution, Longin and Solnik (2001) interpreted these findings as rejection of normality for large negative returns and non-rejection for large positive returns. In the conclusion of their article, Longin and Solnik stress that their approach has the disadvantage of not $\overline{H^{-}}$and $H^{+}$by considering negative points for $H^{-}$and nonnegative points for $H^{+}$such that $H^{2}=\left(H^{-}\right)^{2}$ $+\left(H^{+}\right)^{2}$. They can therefore conclude to asymmetry if $H^{-}$differs from $H^{+}$. 
explicitly specifying the class of return-generating processes that fail to reproduce these two facts. The difficulty in telling which model can reproduce these facts is the lack of analytical expressions for the asymptotic exceedance correlation and its intractability even for classical models such as Gaussian GARCH or regime switching models. In order to investigate this issue, we introduce the concept of tail dependence. This will help us show analytically that some classes of models previously used in the literature cannot reproduce these asymmetries in extreme dependence and then propose a model that succeeds in doing so.

\subsection{Tail Dependence}

To measure the dependence between an extreme event on one market and a similar event on another market, we define two dependence functions one for the lower tail and one for the upper tail, with their corresponding asymptotic tail dependence coefficients. For two random variables $X$ and $Y$ with cumulative distribution functions $F_{X}$ and $F_{Y}$ respectively, we call the lower tail dependence function (TDF) the conditional probability $\tau^{L}(\alpha) \equiv$ $\operatorname{Pr}\left[X \leq F_{X}^{-1}(\alpha) \mid Y \leq F_{Y}^{-1}(\alpha)\right]$ for $\alpha \in(0,1 / 2]$ and similarly, the upper tail dependence function is $\tau^{U}(\alpha) \equiv \operatorname{Pr}\left[X \geq F_{X}^{-1}(1-\alpha) \mid Y \geq F_{Y}^{-1}(1-\alpha)\right] .^{7}$ The tail dependence coefficient (TDC) is simply the limit (when it exists) of this function when $\alpha$ tends to zero. More precisely lower TDC is $\tau^{L}=\lim _{\alpha \rightarrow 0} \tau^{L}(\alpha)$ and upper TDC is $\tau^{U}=\lim _{\alpha \rightarrow 0} \tau^{U}(\alpha)$. As in the case of joint normality, we have lower tail-independence when $\tau^{L}=0$ and upper tail-independence for $\tau^{U}=0$.

Compared to exceedance correlation used by Longin and Solnik (2001), Ang and Chen (2002), Ang and Bekaert (2002), and Patton (2004), a key advantage of TDF and corresponding TDCs is their invariance to modifications of marginal distributions that do not affect the dependence structure. Figure 2 gives an illustration of this invariance. We simulate a bivariate Gaussian distribution $N\left(0, I_{\rho}\right)$, where $I_{\rho}$ is the bi-dimensional matrix with standard deviations equal to one on the diagonal and a correlation coefficient $\rho$ equal to 0.5 . Both exceedance correlation and tail dependence measures show a symmetric behavior of dependence in extreme returns. However, when we replace one of the marginal distributions $N(0,1)$ by a mixture of normals, a $N(0,1)$ and a $N(4,4)$ with equal weights, and let the other marginal distribution and the dependence structure unchanged, the TDF remains the

\footnotetext{
${ }^{7}$ In the literature (see Rodriguez, 2004 and references therein), only the limit of this function is considered. Here, we define the TDF for every $\alpha \in(0,1 / 2]$ to make a comparison with conditional correlation, which is also a function of a threshold. The tail dependence measure is also related to the concept of lower (upper) orthant dependence concept (see Denuit and Scaillet, 2004).
} 
same while the exceedance correlation is affected. In fact, the correlation coefficient and the exceedance correlation are a function of the dependence structure and of the marginal distributions while the tail dependence is a sole function of the dependence structure, regardless of the marginal distributions. Another disadvantage of exceedance correlation is that asymptotic exceedance correlation cannot be estimated without sample bias since fewer data points are available when we move further into the tails of the distribution. ${ }^{8}$ With tail dependence, the estimation is done using all data points in the sample and the estimators of the tail coefficients are unbiased.

By observing that for the logistic function used by Longin and Solnik (2001), the zero value for the asymptotic correlation coefficient is exactly equivalent to tail independence, we can reformulate their asymptotic result as follow : lower extreme returns are tail-dependent, while upper extreme returns are tail-independent. ${ }^{9}$

This reformulation presents at least two main advantages. Compared to exceedance correlation, the tail dependence coefficient is generally easier to compute and analytical expressions can be obtained for almost all distributions. This is not the case for exceedance correlation even for usual distributions. Moreover, we can easily derive the tail dependence of a mixture from the tail dependence of the different components of the mixture. The last property will be used below to investigate which model can or cannot reproduce the results of Longin and Solnik (2001).

\subsection{Why classical multivariate GARCH and RS model cannot reproduce asymptotic asymmetries?}

Ang and Chen (2002) and Ang and Bekaert (2002) try to reproduce asymmetric correlations facts with classical models such as GARCH and RS based on a multivariate normal distribution. After examining a number of models, they found that GARCH with constant correlation and fairly asymmetric GARCH cannot reproduce the asymmetric correlations documented by Longin and Solnik. However, they found that a RS model with Gaussian innovations is better at reproducing asymmetries in exceedance correlation. They clearly reproduce asymmetric correlations at finite distance. However, their finite-distance asym-

\footnotetext{
${ }^{8}$ Longin and Solnik (2001) determine by simulation an optimal threshold and use the subsample beyond this threshold to estimate the asymptotic exceedance correlation. However, this shortcoming does not compromise the results of Longin and Solnik (2001) since they choose different levels of threshold and still obtain the same result.

${ }^{9}$ For the logistic function with parameter $\alpha$, the correlation coefficient of extremes is $1-\alpha^{2}$ (see Longin and Solnik, 2001). We find that the upper tail dependence coefficient is $2-2^{\alpha}$. Then, both coefficients are zero when $\alpha$ equals 1 and different from zero when $\alpha$ is different from 1 .
} 
metric correlation comes from the asymmetries produced in the marginal distributions with a regime switching in means, as suggested by the simulation in the previous section. ${ }^{10}$ Therefore it becomes difficult to distinguish asymmetries in dependence from asymmetry in marginal distributions. This is a problem of practical relevance since most return series exhibit asymmetry in volatility.

By reinterpreting Longin and Solnik (2001) results in term of TDC instead of asymptotic exceedance correlation, we show analytically that all these models cannot reproduce asymptotic asymmetry even if some can reproduce finite distance asymmetry. These results are extended to the rejection of more general classes of return-generating processes. The key point of this result is the fact that many classes of models including Gaussian(or Student) GARCH and RS can be seen as mixtures of symmetric distributions. We establish the following result.

\section{Proposition 2.1:}

(i) Any GARCH model with constant mean and symmetric conditional distribution has a symmetric unconditional distribution and hence a symmetric TDC.

(ii) If the conditional distribution of a RS model has a zero TDC, then the unconditional distribution also has a zero TDC.

(iii) From a multivariate distribution with symmetric TDC, it is impossible to construct an asymmetric TDC with a mixture procedure (as GARCH, RS or any other) by keeping all marginal distributions unchanged across mixture components.

Proof: see Appendix A.

This proposition allows us to argue that the classical GARCH or RS models cannot reproduce asymmetries in asymptotic tail dependence. Therefore, the classical GARCH models (BEKK, CCC or DCC) with constant mean can be seen as a mixture of symmetric distributions with the same first moments and therefore exhibit a symmetric tail dependence function as well as a symmetric TDC. ${ }^{11}$ When the mean becomes time-varying as in the GARCH-M model the unconditional distribution can allow asymmetry in correlation

\footnotetext{
${ }^{10}$ Ang and Bekaert (2002) note that the ability of a RS model (compared to a GARCH model) to reproduce asymmetries comes from the fact that it accounts for the persistence in both first and second moments. The GARCH model accounts for this persistence only in second moments. We provide analytical arguments to support this intuition.

${ }^{11}$ The BEKK proposed by Engle and Kroner (1995) is a straightforward generalization of the GARCH model to a multivariate case which guarantees positive definiteness of the conditional variance-covariance matrix. In the CCC model proposed by Bollerslev (1990) the correlation matrix is assumed to be constant, while in the DCC of Engle (2002) this matrix is dynamic.
} 
(Ang and Chen, 2002), but this asymmetry comes from the mixture of the marginal distributions. The resulting skewness cannot be completely disentangled from the asymmetric correlation, since correlations are affected by marginal changes. Similarly, the classical RS model with Gaussian innovations is a discrete mixture of normal distributions which has a TDC equal to zero on both sides. Therefore, by (ii) we argue that both its TDCs are zero. However, at finite distance, when the mean changes with regimes, the exceedance correlation is not symmetric. This asymmetry is found by Ang and Chen (2002) and Ang and Bekaert (2002) in their RS model, but it disappears asymptotically and it comes from the asymmetry created in the marginal distributions by regime switching in means. Hence, the asymmetries in correlation are not separable from the marginal asymmetry, exactly like in the GARCH-M case. The part (iii) of proposition 2.1 extends this intuition in terms of more general multivariate mixture models based on symmetric innovations. Actually when the marginal distributions are the same across all symmetric TDC components of a mixture, it is impossible to create asymmetry in TDCs.

Two relevant issues arise from the above discussion. First, how can we separate the marginal asymmetries from the asymmetry in dependence? Second, how can we account not only for asymmetries at finite distance but also for asymptotic dependence? In the next section, we propose a flexible model based on copulas that addresses these two issues.

\section{A Copula Model for Asymmetric Dependence}

Our model aims at capturing the type of asymmetric dependence found in international equity markets. Our discussion in the last section showed that it is important to disentangle the marginal distributions from the dependence structure. Therefore, we need to allow for asymmetry in tail dependence, regardless of the possible marginal asymmetry or skewness. Copulas, also known as dependence functions, are an adequate tool to achieve this aim.

\subsection{Disentangling the marginal distributions from dependence with cop- ulas}

Estimation of multivariate models is difficult because of the large number of parameters involved. Multivariate GARCH models are a good example since the estimation becomes intractable when the number of series being modeled is high. The CCC of Bollerslev (1990), the DCC of Engle (2002), and the RSDC of Pelletier (2004) deal with this problem by separating the variance-covariance matrix into two parts, one for the univariate variances of the different marginal distributions, the other for the correlation coefficients. This separation 
allows them to estimate the model in two steps. In the first step, they estimate the marginal parameters and use them in the estimation of the correlation parameters in a second step. Copulas offer a tool to generalize this separation while extending the linear concept of correlation to nonlinear dependence.

Copulas are functions that build multivariate distribution functions from their unidimensional margins. Let $X \equiv\left(X_{1}, \ldots, X_{n}\right)$ be a vector of $n$ univariate variables. Denoting $F$ the joint $n$-dimensional distribution function and $F_{1}, \ldots, F_{n}$ the respective margins of $X_{1}, \ldots, X_{n}$. Then the Sklar theorem states that there exists a function $C$ called copula which joins $F$ to $F_{1}, \ldots, F_{n}$ as follows. ${ }^{12}$

$$
F\left(x_{1}, \ldots, x_{n}\right)=C\left(F_{1}\left(x_{1}\right), \ldots, F_{n}\left(x_{n}\right)\right)
$$

This relation can be expressed in term of densities by differentiating with respect to all arguments. We can therefore write (3.1) equivalently as

$$
f\left(x_{1}, \ldots, x_{n}\right)=c\left(F_{1}\left(x_{1}\right), \ldots, F_{n}\left(x_{n}\right)\right) \times \prod_{i=1}^{n} f_{i}\left(x_{i}\right)
$$

where $f$ represents the joint density function of the $n$-dimensional variable $X$ and $f_{i}$ the density function of the variable $X_{i}$ for $i=1, \ldots, n$. The copula density function is naturally defined by $c\left(u_{1}, \ldots, u_{n}\right) \equiv \frac{\partial^{n}}{\partial u_{1} \ldots \partial u_{n}} C\left(u_{1}, \ldots, u_{n}\right)$. Writing the joint distribution density in the above form, we understand why it can be said that a copula contains all information about the dependence structure. ${ }^{13}$

We now suppose that our joint distribution function is parametric and we separate the marginal parameters from the copula parameters. So the relation (3.2) can be expressed as:

$$
\begin{aligned}
f\left(x_{1}, \ldots, x_{n} ; \delta, \theta\right) & =c\left(u_{1}, \ldots, u_{n} ; \theta\right) \times \prod_{i=1}^{n} f_{i}\left(x_{i} ; \delta_{i}\right) \\
u_{i} & =F_{i}\left(x_{i} ; \delta_{i}\right) \quad \text { for } i=1, \ldots, n
\end{aligned}
$$

where $\delta=\left(\delta_{1}, \ldots, \delta_{n}\right)$ are the parameters of the different margins and $\theta$ denotes the vector of all parameters that describe dependence through the copula. Therefore, copulas offer a way to separate margins from the dependence structure and to build more flexible multivariate distributions.

\footnotetext{
${ }^{12}$ See Nelsen (1999) for a general presentation. Note that if $F_{i}$ is continuous for any $i=1, \ldots, n$ then the copula $C$ is unique.

${ }^{13}$ The tail dependence coefficients are easily defined through a copula as $\tau^{L}=\lim _{\alpha \rightarrow 0} \frac{C(\alpha, \alpha)}{\alpha}$ and $\tau^{U}=$ $\lim _{\alpha \rightarrow 0} \frac{2 \alpha-1+C(1-\alpha, 1-\alpha)}{\alpha}$.
} 
More recent work allow some dynamics in dependence. In a bivariate context, Rodriguez (2007) introduces regime switching in both the parameters of marginal distributions and the copula function. ${ }^{14}$ Jondeau and Rockinger (2006) capture the time-varying volatilities of the individual equity index return series by a GARCH model and introduce Markovswitching Student-t copulas for pairs of countries. Ang and Bekaert (2002; 2004) allow all parameters of the multivariate normal distribution to change with the regime. The extension of these models to a large number of series faces the above-mentioned curse of dimensionality. Since the switching variable is present in both the margins and the dependence function, separation of the likelihood function into two parts is not possible and the two-step estimation cannot be performed. Pelletier (2004) uses the same separation as in the CCC or DCC and introduces the regime switching variable only in the correlation coefficients. By doing so, he can proceed with the two-step procedure to estimate the model while limiting the number of parameters to be estimated. ${ }^{15}$ We carry out a similar idea but for nonlinear dependence.

Therefore, we separate the modeling of marginal distributions from the modeling of dependence by using univariate GARCH models for the marginal distributions and introducing changes in regime in the copula dependence structure. The pattern of the model with four variables (two countries, two markets in our following application) is illustrated in Figure 3. The four marginal distributions are linked through a dependence function with two regimes, one symmetric, the other asymmetric.

\subsection{Specification of the Marginal Distributions}

For marginal distributions, we use a M-GARCH $(1,1)$ model similar to Heston-Nandi $(2000)$ :

$$
\begin{aligned}
x_{i, t} & =\mu_{i}+\lambda_{i} \sigma_{i, t}^{2}+\sigma_{i, t} z_{i, t} ; \quad z_{i, t} \sim N(0,1) ; \quad i=1, \cdots, 4 \\
\sigma_{i, t}^{2} & =\omega_{i}+\beta_{i} \sigma_{i, t-1}^{2}+\alpha_{i}\left(z_{i, t-1}-\gamma_{i} \sigma_{i, t-1}\right)^{2} .
\end{aligned}
$$

The variables $x_{1, t}$ and $x_{2, t}$ represent the log returns of equities and bonds respectively for the first country while $x_{3, t}$ and $x_{4, t}$ are the corresponding series for the second country; $\sigma_{i, t}^{2}$ denotes the conditional variance of $x_{i, t}, \lambda_{i}$ can be interpreted as the price of risk and $\gamma_{i}$

\footnotetext{
${ }^{14}$ The models proposed by Rodriguez (2004) in his analysis of contagion can reproduce asymmetric dependence but it cannot distinguish between skewness and asymmetry in the dependence structure. In fact, a change in regime produces both skewness and asymmetric dependence, two different features that must be characterized separately. The analysis is limited to pairs of stock markets in Asia and Latin America.

${ }^{15}$ Since Pelletier (2004) uses the normal distribution with constant mean, the resulting unconditional distribution is symmetric and cannot reproduce asymmetric dependence.
} 
captures potential asymmetries in the volatility effect. ${ }^{16}$ In the Heston-Nandi (2000) interpretation, $\mu_{i}$ represents the interest rate. ${ }^{17}$ The parameters of the marginal distributions are grouped into one vector $\delta \equiv\left(\delta_{1}, \cdots, \delta_{4}\right)$, with $\delta_{i}=\left(\mu_{i}, \lambda_{i}, \omega_{i}, \beta_{i}, \alpha_{i}, \gamma_{i}\right)$.

\subsection{Specification of the Dependence Structure}

Our dependence model is characterized by two regimes, one Gaussian regime in which dependence is symmetric $\left(C_{N}\right)$ and a second regime that can capture the asymmetry in extreme dependence $\left(C_{A}\right)$. The conditional copula is given by:

$$
C\left(u_{1, t}, \ldots, u_{4, t} ; \rho^{N}, \rho^{A} \mid s_{t}\right)=s_{t} C_{N}\left(u_{1, t}, \ldots, u_{4, t} ; \rho^{N}\right)+\left(1-s_{t}\right) C_{A}\left(u_{1, t}, \ldots, u_{4, t} ; \rho^{A}\right),
$$

where $u_{i, t}=F_{i t}\left(x_{i, t} ; \delta_{i}\right)$, with $F_{i t}$ denoting the conditional cumulative distribution function of $x_{i, t}$ given the past observations. The variable $s_{t}$ follows a Markov chain with a constant transitional probability matrix.

$$
M=\left(\begin{array}{ll}
P & 1-P \\
1-Q & Q
\end{array}\right) ; P=\operatorname{Pr}\left(s_{t}=1 \mid s_{t-1}=1\right) \text { and } Q=\operatorname{Pr}\left(s_{t}=0 \mid s_{t-1}=0\right)
$$

The normal regime $\left(s_{t}=1\right)$ corresponds to the symmetric regime where the conditional joint normality can be supported and the asymmetric regime $\left(s_{t}=0\right)$ corresponds to the asymmetric regime in which markets are strongly more dependent for large negative returns than for large positive returns.

The Gaussian copula $C_{N}$ is defined straightforwardly by (3.1) where the joint distribution $F=\Phi_{\rho^{N}}$ is the 4-dimensional normal cumulative distribution function with all diagonal elements of the covariance matrix equal to one, i.e. $C_{N}\left(u_{1}, \ldots, u_{4} ; \rho^{N}\right)=$ $\Phi_{\rho^{N}}\left(\Phi^{-1}\left(u_{1}\right), \ldots, \Phi^{-1}\left(u_{4}\right)\right)$, where $\Phi$ is the univariate standard normal cumulative distribution function.

The asymmetric components of the copula are illustrated in Figure 4. The first one is characterized by independence between the two countries, but possibly extreme dependence between equities and bonds for each country. The second one is characterized by independence between equity and bond markets but allows for extreme dependence between equity returns and bond returns separately. The third one allows for possible extreme dependence

\footnotetext{
${ }^{16}$ The condition $\beta_{i}+\alpha_{i} \gamma_{i}^{2}<1$ is sufficient to have the stationarity of the process $x_{i, t}$ with finite unconditional mean and variance (see Heston and Nandi, 2000).

${ }^{17}$ Here we keep $\mu_{i}$ as a free parameter to give more flexibility to our model.
} 
between bonds in one country and equities in another country but supposes independence for the rest.

Formally, the asymmetric copula is the mixture of these three components and is expressed as follows:

$$
\begin{aligned}
C_{A}\left(u_{1}, \ldots, u_{4} ; \rho^{A}\right) \equiv & \pi_{1} C_{G S}\left(u_{1}, u_{2} ; \tau_{1}^{L}\right) \times C_{G S}\left(u_{3}, u_{4} ; \tau_{2}^{L}\right) \\
& +\pi_{2} C_{G S}\left(u_{1}, u_{3} ; \tau_{3}^{L}\right) \times C_{G S}\left(u_{2}, u_{4} ; \tau_{4}^{L}\right) \\
& +\left(1-\pi_{1}-\pi_{2}\right) C_{G S}\left(u_{1}, u_{4} ; \tau_{5}^{L}\right) \times C_{G S}\left(u_{2}, u_{3} ; \tau_{6}^{L}\right)
\end{aligned}
$$

with $\rho^{A}=\left(\pi_{1}, \pi_{2}, \tau_{1}^{L}, \tau_{2}^{L}, \tau_{3}^{L}, \tau_{4}^{L}, \tau_{5}^{L}, \tau_{6}^{L}\right)$, and the bivariate component is the Gumbel survival copula given by

$$
C_{G S}\left(u, v ; \tau^{L}\right)=u+v-1+\exp \left[-\left((-\log (1-u))^{\theta\left(\tau^{L}\right)}+(-\log (1-v))^{\theta\left(\tau^{L}\right)}\right)^{1 / \theta\left(\tau^{L}\right)}\right]
$$

where $\theta\left(\tau^{L}\right)=\frac{\log (2)}{\log \left(2-\tau^{L}\right)}, \tau^{L} \in[0,1)$ is the lower TDC and the upper TDC is zero. ${ }^{18}$

One can notice that our asymmetric copula specification implies some restrictions in the dependence structure. For three different couples from different components of this copula, the sum of their TDC is lower than one. ${ }^{19}$ Without any restrictions this sum may reach 3. Such restrictions are dictated by some copula limitations. ${ }^{20}$ A major problem in multivariate distributions' construction today and perhaps the most important open question concerning copulas as mentioned by Nelsen (1999, page 86) is how to construct multivariate copulas with specific bivariate marginal distributions. ${ }^{21}$ A theorem by Genest et al. (1995) states that it is not always possible to construct multivariate copulas with given bivariate margins. Therefore, even if in the bivariate case we can have a nice asymmetric copula with lower tail dependence and upper tail independence as Longin and Solnik (2001) suggest, some

\footnotetext{
${ }^{18}$ The Longin and Solnik (2001) result implies that lower tails are dependent while upper tails are independent. Hence, the Gumbel survival copula is designed to model this feature since it has this tail dependence structure.

${ }^{19}$ For example, the TDC between bonds and equities in the first country is $\pi_{1} \tau_{1}^{L}$, between equities of two countries $\pi_{2} \tau_{3}^{L}$, and between equities in the first country and bonds in the second country $\left(1-\pi_{1}-\pi_{2}\right) \tau_{5}^{L}$. Therefore, the sum is $\pi_{1} \tau_{1}^{L}+\pi_{2} \tau_{3}^{L}+\left(1-\pi_{1}-\pi_{2}\right) \tau_{5}^{L} \leq 1$, since $\tau_{1}^{L} \leq 1, \tau_{3}^{L} \leq 1$, and $\tau_{5}^{L} \leq 1$.

${ }^{20}$ This model can be generalized in the same way to a copula of any dimension.

${ }^{21}$ Aas, Czado, Frigessi, and Bakken (2007) propose an approach to build multiple dependence based on pair-copula decomposition. Their approach proceeds by a hierarchical incorporation of more variables in the conditioning sets. This procedure provides a nice way to build flexible multivariate copula. In practice it is important to make a good choice of couples that should be used in the first level of the hierarchy since a limitation of the procedure is that the couples after the first level of the hierarchy are based on conditional copulas.
} 
problems remain when we contemplate more than two series. Most existing asymmetric tail dependent copulas are in the family of archimedean copulas and the usual straightforward generalization in multivariate copulas constrains all bivariate marginal copulas to be the same. This is clearly not admissible in the context of our analysis. In the above model, we allow each of the six couples of interest to have different levels of lower TDC. As $C_{A}$ is constructed, it is easy to check that it is a copula since each component of the mixture is a copula and the mixture of copulas is a copula. ${ }^{22}$

It is important to notice that, in this model, the labeling of each regime is defined ex-ante. The normal regime $\left(s_{t}=1\right)$ corresponds to the symmetric regime where the conditional joint normality can be supported and the asymmetric regime $\left(s_{t}=0\right)$ corresponds to the asymmetric regime in which markets are strongly more dependent for large negative returns than for large positive returns.

\subsection{An adapted parsimonious model}

Given our application, we impose an additional constraint: $\pi_{1}+\pi_{2}=1$. This means that we neglect the asymmetric cross-dependence between equities in one country and bonds in another country. However, it should be stressed that we maintain cross-country dependence through the normal regime. We will verify in any case if this restriction is supported by the data or not ${ }^{23}$. The mixed copula becomes:

$$
\begin{aligned}
C_{A}\left(u_{1}, \ldots, u_{4} ; \rho^{A}\right) \equiv & \pi C_{G S}\left(u_{1}, u_{2} ; \tau_{1}^{L}\right) \times C_{G S}\left(u_{3}, u_{4} ; \tau_{2}^{L}\right) \\
& +(1-\pi) C_{G S}\left(u_{1}, u_{3} ; \tau_{3}^{L}\right) \times C_{G S}\left(u_{2}, u_{4} ; \tau_{4}^{L}\right)
\end{aligned}
$$

Therefore, the asymmetric copula is now characterized by just five parameters $\rho^{A}=$ $\left(\pi, \tau_{1}^{L}, \tau_{2}^{L}, \tau_{3}^{L}, \tau_{4}^{L}\right)$.

\subsection{Estimation}

As already mentioned, our structure allows for a two-step estimation procedure. The likelihood function must be evaluated unconditionally to the unobservable regime variable $s_{t}$ and

\footnotetext{
${ }^{22}$ A copula can be seen as the cdf of a multidimensional variable with uniform $[0,1]$ margins. If we consider two bivariate independent variables with uniform margins the copula linking the four variables is simply the product of the corresponding bivariate copulas. Hence, such a product is always a copula.

${ }^{23}$ A related study by Hartmann, Straeman, and De Vries (2004) using extreme value theory tends to support this restriction. Analyzing stock and bond returns for G-5 countries, they find that extreme dependence between stocks and bonds is much lower that extreme dependence between stock markets or bond markets. This is especially the case for cross-country dependence between stocks in one country and bonds in another country.
} 
decomposed in two parts. Let us denote the sample of observed data by $\underline{X}_{T}=\left\{X_{1}, \cdots, X_{T}\right\}$ where $X_{t} \equiv\left\{x_{1, t}, \cdots, x_{4, t}\right\}$. The log likelihood function is given by:

$$
L\left(\delta, \theta ; \underline{X}_{T}\right)=\sum_{t=1}^{T} \log f\left(X_{t} ; \delta, \theta \mid \underline{X}_{t-1}\right)
$$

where $\underline{X}_{t-1}=\left\{X_{1}, \ldots X_{t-1}\right\}$ and $\theta$ is a vector including the parameters of the copula and the transition matrix. Hamilton (1989) describes a procedure to perform this type of evaluation $^{24}$. With $\xi_{t}=\left(s_{t}, 1-s_{t}\right)^{\prime}$ and denoting

$$
\eta_{t}=\left[\begin{array}{l}
f\left(X_{t} ; \delta, \theta \mid \underline{X}_{t-1}, s_{t}=1\right) \\
f\left(X_{t} ; \delta, \theta \mid \underline{X}_{t-1}, s_{t}=0\right)
\end{array}\right]
$$

the density function conditionally to the regime variable $s_{t}$ and the past returns can be written as:

$$
f\left(X_{t} ; \delta, \theta \mid \underline{X}_{t-1}, s_{t}\right)=\xi_{t}^{\prime} \eta_{t}
$$

Since $s_{t}\left(\right.$ or $\left.\xi_{t}\right)$ is unobservable, we integrate on $s_{t}$ and obtain the unconditional density function:

$$
\begin{aligned}
f\left(X_{t} ; \delta, \theta \mid \underline{X}_{t-1}\right)= & \operatorname{Pr}\left[s_{t}=1 \mid \underline{X}_{t-1} ; \delta, \theta\right] \times f\left(X_{t} ; \delta, \theta \mid \underline{X}_{t-1}, s_{t}=1\right) \\
& +\operatorname{Pr}\left[s_{t}=0 \mid \underline{X}_{t-1} ; \delta, \theta\right] \times f\left(X_{t} ; \delta, \theta \mid \underline{X}_{t-1}, s_{t}=0\right)
\end{aligned}
$$

The conditional probabilities of being in different regimes at time $t$ conditional on observations up to time $t-1$, denoted by $\widehat{\xi}_{t \mid t-1} \equiv\left(\operatorname{Pr}\left[s_{t}=1 \mid \underline{X}_{t-1} ; \delta, \theta\right], \operatorname{Pr}\left[s_{t}=0 \mid \underline{X}_{t-1} ; \delta, \theta\right]\right)^{\prime}$, are computed through the Hamilton filter. Starting with the initial value $\widehat{\xi}_{1 \mid 0}$, the optimal inference and forecast for each date in the sample is given by the iterative equations:

$$
\begin{aligned}
\widehat{\xi}_{t / t} & =\left[\widehat{\xi}_{t \mid t-1}^{\prime} \eta_{t}\right]^{-1}\left(\widehat{\xi}_{t \mid t-1} \odot \eta_{t}\right), \\
\widehat{\xi}_{t+1 / t} & =M^{\prime} \cdot \widehat{\xi}_{t \mid t}
\end{aligned}
$$

where $\odot$ denotes element-by-element multiplication. Finally, the unconditional density can be evaluated with the observed data as $f\left(X_{t} ; \delta, \theta \mid \underline{X}_{t-1}\right)=\widehat{\xi}_{t \mid t-1}^{\prime} \eta_{t}$ and the log likelihood becomes:

$$
L\left(\delta, \theta ; \underline{X}_{T}\right)=\sum_{t=1}^{T} \log \left(\widehat{\xi}_{t \mid t-1}^{\prime} \eta_{t}\right) .
$$

\footnotetext{
${ }^{24}$ A general presentation can be found in Hamilton (1994, chapter 22).
} 
To perform the two-step procedure, we decompose the log likelihood function into two parts: the first part includes the likelihood functions of all margins, while the second part represents the likelihood function of the copula.

Proposition 3.2 (Decomposition of the log likelihood function) The log likelihood function can be decomposed into two parts including the margins and the copula

$$
L\left(\delta, \theta ; \underline{X}_{T}\right)=\sum_{i=1}^{4} L_{i}\left(\delta_{i} ; \underline{X}_{i, T}\right)+L_{C}\left(\delta, \theta ; \underline{X}_{T}\right)
$$

where

$$
\begin{gathered}
\underline{X}_{i, t}=\left\{x_{i, 1}, \ldots, x_{i, t}\right\} \\
L_{i}\left(\delta_{i} ; \underline{X}_{i, T}\right)=\sum_{t=1}^{T} \log f_{i}\left(x_{i, t} ; \delta_{i} \mid \underline{X}_{i, t-1}\right) \\
L_{C}(\delta, \theta ; X)=\sum_{t=1}^{T} \log \left(\widehat{\xi}_{t \mid t-1}^{\prime} \eta_{c t}\right)
\end{gathered}
$$

with

$$
\eta_{c t}=\left[\begin{array}{c}
c\left(u_{1, t}\left(\delta_{1}\right), \ldots, u_{n, t}\left(\delta_{n}\right) ; \theta \mid s_{t}=1\right) \\
c\left(u_{1, t}\left(\delta_{1}\right), \ldots, u_{n, t}\left(\delta_{n}\right) ; \theta \mid s_{t}=0\right)
\end{array}\right] ; \quad u_{i, t}\left(\delta_{i}\right)=F_{i}\left(x_{i, t} ; \delta_{i} \mid \underline{X}_{i, t-1}\right)
$$

and $\widehat{\xi}_{t \mid t-1}^{\prime}$ filtered from $\eta_{c t}$ as

$$
\begin{aligned}
& \widehat{\xi}_{t / t}=\left[\widehat{\xi}_{t \mid t-1}^{\prime} \eta_{c t}\right]^{-1}\left(\widehat{\xi}_{t \mid t-1} \odot \eta_{c t}\right) \\
& \widehat{\xi}_{t+1 / t}=M^{\prime} \cdot \widehat{\xi}_{t \mid t}
\end{aligned}
$$

Proof: see Appendix A.

Several options are available for the estimation of the initial value $\widehat{\xi}_{1 \mid 0}$. One approach is to set it equal to the vector of unconditional probabilities, which is the stationary transitional probability of the Markov chain. Another simple option is to set $\widehat{\xi}_{1 \mid 0}=N^{-1} 1_{N}$. Alternatively it could be considered as another parameter, which will be estimated subject to the constraint that $1_{N}^{\prime} \widehat{\xi}_{1 \mid 0}=1$. We will use the first option here.

Through the above decomposition, we notice that each marginal log likelihood function is separable from the others. Therefore, even if the estimation of all margins is performed in a first step, we can estimate each set of marginal parameters separately into this step. The first step is then equivalent to $n$ single estimations of univariate distributions. The two-step estimation is formally written as follows: 


$$
\begin{aligned}
\widehat{\delta} & =\underset{\delta=\left(\delta_{1}, \ldots, \delta_{4}\right) \in \Delta}{\arg \max } \sum_{i=1}^{4} L_{i}\left(\delta_{i} ; X_{i, .}\right), \\
\widehat{\theta} & =\underset{\theta \in \Theta}{\arg \max } L_{C}(\widehat{\delta}, \theta ; X) .
\end{aligned}
$$

The estimator for the parameters of the marginal distributions is then $\widehat{\delta}=\left(\widehat{\delta}_{1}, \ldots, \widehat{\delta}_{4}\right)$, with $\widehat{\delta}_{i}=\left(\widehat{\mu}_{i}, \widehat{\lambda}_{i}, \widehat{\omega}_{i}, \widehat{\beta}_{i}, \widehat{\alpha}_{i}, \widehat{\gamma}_{i}\right)^{\prime} ;$ and $\widehat{\theta}=\left(\widehat{\rho}^{N} ; \widehat{\rho}^{A} ; \widehat{P} ; \widehat{Q}\right)$ includes all estimators of the parameters involved in the dependence structure. $\Delta$ and $\Theta$ represent the sets of all possible values of $\delta$ and $\theta$ respectively.

\subsection{Testing asymmetry in dependence}

While the proposed copula model has the potential to capture asymmetry in dependence, we need to test formally for the presence of such asymmetric dependence. The natural way to evaluate whether dependence is asymmetric is to test the null hypothesis of one normal copula regime $\left(H_{0}:(P=1\right.$ and $Q=0)$, where $P$ and $Q$ are the parameters of the transition probability matrix), against the alternative hypothesis of two-copula regimes including the normal one and the asymmetric one. This test faces many irregularity problems. Under the null hypothesis, some nuisance parameters are unidentified and the scores are identically zero. These are the general problems of testing in RS models.

Hansen (1996) describes the asymptotic distributions of standard test statistics in the context of regression models with additive nonlinearity. Garcia (1998) and Hansen (1992) provide the asymptotic null distribution of the likelihood ratio test. Andrews and Ploberger (1993) address the first problem in a general context and derive an optimal test. The above procedures solve the problem of unidentified nuisance parameters under the null and the identically zero scores. However, there is an additional problem of testing parameter on the boundary. Andrews (2001) deals with this boundary problem but in the absence of the first two problems.

Maximized Monte Carlo (MMC) tests of Dufour (2005), which are a generalization of classical Monte Carlo (MC) tests of Dwass (1957) and Barnard (1963), are adapted for tests facing all these problems. The MC tests of Dwass (1957) and Barnard (1963) are performed by doing many replications (with the same sample size as the data sample) under the null hypothesis, and compute the test statistic for each replication. The distribution of the test statistic is therefore approximated by the distribution of the obtained values. One can therefore compute the value of the test statistic with the data and deduce from the MC 
distribution the p-value of the test. The classical MC test does not deal with the presence of nuisance parameters under the null hypothesis. The MMC of Dufour (2005) addresses the problem of nuisance parameters under the null. When the test statistic involves the nuisance parameters as in the case of the likelihood ratio test under the alternative, the values of these parameters are needed to compute the test statistic on simulated data.

The MMC technique is the maximization of the p-values given all the possible values of the nuisance parameters. This test is computationally very demanding. However, Dufour (2005) proposes a simplified version that focuses on the estimated values of the nuisance parameters and shows that it works under the assumptions of uniform continuity, and convergence over the nuisance parameter space. Our model satisfies these assumptions of uniform continuity and convergence. Therefore, we can apply this simpler version also known as parametric bootstrap test.

\section{Dependence structure in international bond and equity markets: an empirical investigation}

\subsection{Data}

We will consider the same model for two pairs of two countries. First, we model the equity and bond markets in the United States and Canada. The US equity returns are based on the SP 500 index, while the Canadian equity returns are computed with the Datastream index. The bond series are indices of five-year government bonds computed by Datastream. These bond indices are available daily and are chain-linked allowing the addition and removal of bonds without affecting the value of the index.

We also consider France and Germany as a pair of countries. An additional interest here will be to see how the introduction of the European common currency changed the dependence structure between the asset markets in these two countries. The bond indices are the Datastream five-year government bond indices, while the equity indices are the MSCI series.

All returns are total returns and are expressed in US dollars on a weekly basis from January 01, 1985 to December 21, 2004, which corresponds to a sample of 1044 observations. Descriptive statistics are reported in Table 1.

Sharpe ratios appear to be of the same magnitude for both equities and bonds, around 0.6 in average for the first and slightly above 1 for the second. The United States exhibits the highest ratios among the four countries. All return series present negative skewness except for the French bond index. Both mean returns and return volatility are higher in 
France and Germany than in the US and Canada. The volatility of returns in France and Germany is more than $23 \%$, while it is only $18 \%$ in the US and Canada.

Unconditional correlations are reported in Table 2. The US and Canadian markets exhibit relatively high correlations, 0.72 for equities and 0.5 for bonds. The same is true for the France-Germany pair, although the bond markets are tightly linked, with a correlation of 0.94. The North-American equity markets are less correlated with European equity markets (around 0.2) than their bond counterparts (around 0.32). The cross-correlations between equity and bond markets vary from country to country. In average the two markets seem to move independently in the United States, while they are more closely related in Canada (0.44) and in Europe (around 0.3 for both France and Germany). Cross-correlations between equities and bonds in two different countries are not very high for US and Canada, and of the same order of magnitude than within-country cross-correlations (0.3) for France and Germany.

\subsection{Marginal distributions}

The estimates of the marginal parameters are reported in Table 3. The large values for the $\beta_{i}$ parameters (around 90\%) capture the high persistence in volatility. The high degree of significance for the parameter $\lambda$ indicates that asset returns are skewed.

One important assumption for these GARCH models is that the error terms are i.i.d. Therefore, to verify if the assumption is fulfilled, we perform some tests of independence on the residuals. The test results in Table 4 suggest that the independence assumption of residuals cannot be rejected for all series with a good degree of confidence.

\subsection{Dependence structure in bond and equity markets}

Three main conclusions emerge from the empirical results. First, there appears to be a large extreme cross-country dependence for both the equity and bond markets, while there is little dependence between equities and bonds in the same country. Second, the dependence structure exhibits a strong nonlinearity. Third, there seems to be a link between exchange rate volatility and asymmetry of dependence.

\subsubsection{US-Canada Dependence Structure}

In Table 5, we report the results of estimating the dependence model described in section (3.4). The cross-country extreme dependence is large in both equity and bond markets, but the dependence across the two markets is relatively low in both countries. In the asymmetric 
regime, the TDCs are larger than $54 \%$ in both bond-bond and equity-equity markets, while both equity-bond TDCs in US and Canada are lower than 2\%. This observation has an important implication for international diversification. The fact that extreme dependence in international equity and bond markets is larger than national bond-equity dependence can have a negative effect on the gain of international diversification and encourage the switching from equity to the domestic bond or risk-free asset in case of bear markets.

The average absolute value of correlation in the normal regime is larger than $39 \%$ for cross-country dependence and lower than $41 \%$ for equity-bond dependence. In the last case the correlation between bonds and equities in Canada is unusually high. The results underline the differences between unconditional correlation and the correlation in the normal regime. In fact, the presence of extreme dependence in the negative returns explains this difference since the multivariate Gaussian distribution has independence in the tails of returns regardless of the level of correlation.

The separation of the distribution into two parts, including the normal regime and the asymmetric regime, allows to capture the strong nonlinear pattern in the dependence structure. Moreover, it is interesting to see that for a high unconditional correlated couple such as the US and Canada equity markets, this separation gives not only an extreme dependence for the asymmetric regime, but also a high correlation in the normal regime $(87 \%)$ that appears larger than the unconditional correlation (72\%). This result may seem counterintuitive if we take the unconditional correlation as a "mean" of the correlations in the two regimes. Of course, one must realize that the asymmetric regime can be characterized by a low correlation but by a large TDC. This demonstrates the importance of distinguishing between correlation and extreme dependence. The mixture model is better able to capture this distinction in fitting the data. A normal distribution may be a good approximation for measuring finite distance dependence, but an appropriate copula structure is necessary for characterizing extreme dependence.

\subsubsection{France-Germany Dependence Structure}

The estimation results are shown in Table 6. Due to a high cross-country unconditional correlation in both markets, the results for France and Germany are more eloquent. The dependence between equities and bonds is low, while the dependence between assets of the same type is large in both regimes. For France and Germany, equity-equity correlation and bond-bond correlation are larger than $90 \%$ while bond-equity correlations are lower than $21 \%$ in the same country as well as between the two countries. In the asymmetric regime, 
the TDC are larger than $67 \%$ between assets of the same type and lower than 2 percent between bond and equities in both France and Germany ${ }^{25}$.

To analyze the effect of the Euro on the dependence structure, we split the observation period in two sub-periods, before and after the introduction of the currency. Tables 7 and 8 contain the results for the respective subperiods. We find that the introduction of the Euro increases the correlation in the normal regime between the French and German markets. Before the introduction of the Euro, in the normal regime, the cross-country correlation between assets of the same type is in average $80 \%$, against more than $96 \%$ after the introduction. The cross-asset correlations exhibit a similar pattern since all correlations increase after the introduction of the Euro. This result is consistent with those of Cappiello, Engle and Sheppard (2003) who find that the introduction of a fixed exchange rate leads to a structural break characterized by a high correlation. ${ }^{26}$ For the asymmetric regime, the results are more surprising since the extreme dependence between the French and German equity markets drastically decreases from $87 \%$ to $26 \%$. All the other extreme dependence coefficients increase, but only the TDC of the FR bond-DE bond pair increases significantly. Since this change in the level of dependence suggests a relationship between the dependence structure and the exchange rate, we investigate it further in the next section for both pairs of countries.

These results for the two pairs of countries that we analyzed suggest that an asymmetric regime cannot be readily associated with market situations such as bull and bear markets or calm and volatile markets used in the previous literature on contagion. Das and Uppal (2003) relate high volatility and downturn markets to a large conditional correlation ${ }^{27}$, while Forbes and Rigobon (2001) define contagion as a change in correlation during more volatile market times. In an asymmetric regime of dependence, extreme negative shocks are more likely to be transmitted to other markets than positive shocks, irrespective of the market situation. In the normal dependence regime good and bad shocks are transmitted with the same probability.

To conclude, let us mention that the results of the Monte Carlo tests reported in Table 9 reject soundly the absence of asymmetry in the dependence structure with p-values close

\footnotetext{
${ }^{25}$ We also estimated a version of the model where we allowed dependence between equities and bonds across Germany and France but not within each country. We found TDCs even lower than 2 percent, which tends to support our initial assumption to ignore such cross-country dependence across markets.

${ }^{26}$ The goal of Cappiello, Engle and Sheppard (2003) was to investigate the asymmetric effect of past news on the correlation. Since it is well documented that the negative shocks have a larger effect on volatility than the positive shocks of the same magnitude, they try to see if the result is similar for correlation.

${ }^{27}$ Boyer, Gibson, and Loretan (1999), and Forbes and Rigobon (2002) show that there is a theoretical bias when comparing correlations in different market situations
} 
to zero in both pairs of countries.

\subsubsection{Link between asymmetric dependence and the exchange rate}

The filtered probabilities to be in asymmetric regime are obtained as a by-product of estimation. They provide at each time period $t$ a probabilistic assessment of being in the asymmetric regime conditional on the information available at time $t$. For France and Germany, these probabilities show a clear break after the introduction of the Euro. Before its introduction, the dependence is more likely asymmetric and becomes more Gaussian after the event. To investigate this relationship further, we perform a logistic regression of the conditional probabilities to be in the asymmetric regime on the volatility of the exchange rate. $^{28}$

For France and Germany, we have:

$$
\widehat{P}_{t}=\begin{gathered}
a \\
-1.26 \mathrm{e}+0 \\
(6.81 \mathrm{e}-2)
\end{gathered} \quad \begin{gathered}
b .06 \mathrm{e}+2 \\
(2.29 \mathrm{e}+1)
\end{gathered}
$$

The dependent variable is $\widehat{P}_{t}=\log \left(P_{t} /\left(1-P_{t}\right)\right)$, where $P_{t}$ is the conditional probability to be in the asymmetric regime given the time-t available information, and $V o l_{t}$ is the exchange rate volatility between the two countries obtained by a M-GARCH(1,1) filter. Standard deviations are reported between parentheses. The coefficient is positive and highly significant (the $\mathrm{R}^{2}$ of the regression is 0.86 ) suggesting a strong relationship between exchange rate volatility and asymmetric dependence.

One may be concerned that the relation between the probability of the asymmetric regime and exchange rate volatility is due to the correlation of the latter with the volatility of the equity market or the bond market of the respective countries. To address this issue, we perform an orthogonalization. We regress the exchange rate on all equity and bond return volatilities in a first step and keep residuals. Then we regress the probability of asymmetric regime on these residuals in a second step. The relation remains significant.

We run the same regression for US and Canada to investigate if the relation holds when no structural change occurs. The results are similar to the European results.

$$
\widehat{P}_{t}=\begin{gathered}
a \\
-7.71 \mathrm{e}-1 \\
(1.76 \mathrm{e}-1)
\end{gathered} \quad \begin{gathered}
b .30 \mathrm{e}+1 \\
(2.36 \mathrm{e}+1)
\end{gathered}
$$

\footnotetext{
${ }^{28}$ Since the probability $P_{t}$ to be in a regime is between 0 and 1 , the logistic regression allows us to keep this constraint by proceeding as follows $P_{t}=\exp \left(a+V o l_{t}+\varepsilon_{t}\right) /\left(1+\exp \left(a+V o l_{t}+\varepsilon_{t}\right)\right)$ or equivalently $\log \left(P_{t} /\left(1-P_{t}\right)\right)=a+b$ Vol $_{t}+\varepsilon_{t}$ and we can perform the usual regression.
} 
The $R$ - square of the regression remains high at 0.75 .

The fact that high exchange rate volatility is associated with asymmetric dependence appears to be consistent with the results in the literature, since asymmetric dependence was mainly found to be present in international equity markets (see Longin and Solnik, 2001). Our own results suggest the presence of asymmetric dependence in international bond markets as well.

Intuitively, the persistence of each dependence regime depends on the persistence of exchange rate volatility. A high exchange rate volatility increases extreme comovements. When bad news in a country combine with a very active currency market, transmission through the latter makes downside joint movements more likely than in a fixed exchange rate regime. This may provide an insight about the strong change in the persistence of different regimes after the introduction of the Euro. Before, the exchange rate between the French Franc and the German Deutsch Mark was especially volatile and this may explain a strong persistence in the asymmetric regime when the model is estimated over this subperiod. After the introduction of the Euro, the volatility is reduced to zero and the normal regime becomes the only persistent regime. By putting the two subperiods together, both regimes appear persistent, which is consistent with our explanation.

These results are consistent with Capiello, Engle and Sheppard (2003) who find a structural break in the dependence structure of European markets after the introduction of the Euro. They find an increase to a near perfect correlation. However, due to the fact that the dynamic conditional correlation model they use is based on the normal distribution the correlation before the introduction of Euro is misleading since as we find, the dependence between European countries was more asymmetric and therefore the dependence was more in the tail and cannot be completely captured by correlation.

\section{Asymmetric Dependence Effect on International Diversi- fication}

The benefits of international diversification are well documented in the literature, but investors tend to invest mainly in their own country. In fact, the share invested by home investors in domestic assets is much larger than the share predicted by the Mean-Variance (MV) model. Two main explanations have been put forward. Transaction costs for international assets reduce the expected gain on foreign assets, while information asymmetry between local and foreign investors increases the risk of foreign assets. These explanations

affect the first two moments of asset returns. The transaction costs affect the first moment 
by reducing the expected return and the asymmetric information affects the second moment since it increases the risk of foreign assets ${ }^{29}$.

We go beyond the first two moments to investigate the effect of skewness and specially coskewness on cross-country diversification and also on bonds against equities diversification. We show how strong dependence in lower returns in two markets can reduce co-skewness and therefore lower skewness in a portfolio with long positions on both markets. Since the reduction of co-skewness lowers the gains to diversification, investors tend to hold a higher share of low-risk assets than in a MV portfolio.

Two recent studies have examined the portfolio allocation effects of asymmetric correlation or dependence between equities and cash. In a two-regime correlation model, Ang and Bekaert (2004) find that the investor tends to switch to cash when a persistent bear market hits, while Patton (2004) notices a significant gain when an investor takes into account the existence of the asymmetric dependence structure. Here we study analytically the effects of asymmetric dependence on cross-country diversification and on domestic diversification between bonds and equities.

The agent's wealth at time $t$ invested in domestic and foreign bonds and equities is described by the following equation:

$$
W_{t}=W_{t-1}\left[w_{t} \eta_{t}^{h} R_{t}^{h, b}+w_{t}\left(1-\eta_{t}^{h}\right) R_{t}^{h, e}+\left(1-w_{t}\right) \eta_{t}^{f} R_{t}^{f, b}+\left(1-w_{t}\right)\left(1-\eta_{t}^{f}\right) R_{t}^{f, e}\right],
$$

where $R_{t}^{h, b}, R_{t}^{h, e}, R_{t}^{f, b}$, and $R_{t}^{f, e}$ are the returns of domestic bond, domestic equity, foreign bond, and foreign equity respectively. We adopt a specification which simplified the analysis of two above-mentioned effects, cross-country and domestic diversification. So, $w_{t}$ is the share invested in domestic assets, the remaining $\left(1-w_{t}\right)$ being invested in foreign assets, while $\eta_{t}^{h}$ and $\eta_{t}^{f}$ are the shares invested in domestic and foreign bonds respectively.

\subsection{Investor Problem}

To analyze the effects of asymmetric dependence on cross-country and domestic diversification, we assume that the investor has to choose the share $w_{t}$ invested in domestic assets, and the bond shares $\eta_{t}^{h}$ and $\eta_{t}^{f}$. Therefore, the return on his domestic portfolio is $R_{t}^{h}=w_{t} \eta_{t}^{h} R_{t}^{h, b}+w_{t}\left(1-\eta_{t}^{h}\right) R_{t}^{h, e}$, while the return on the foreign portfolio is

\footnotetext{
${ }^{29}$ Glassman and Riddick (2001) perform an empirical assessment of these potential explanations. Using data for six developed countries, they find that to explain the deviations, transaction costs must be in excess of $1 \%$ per month, 14-19\% per year, against the actual estimation of 1-4\% per annum, with some variation across countries (see, e.g., Perold and Sirri, 1994; Solnik, 1996). Moreover, Glassman and Riddick (2001) find that the implied volatility that matches the portfolio data is greater than twice the historical volatility and therefore is unreasonable.
} 
$R_{t}^{f}=\left(1-w_{t}\right) \eta_{t}^{f} R_{t}^{f, b}+\left(1-w_{t}\right)\left(1-\eta_{t}^{f}\right) R_{t}^{f, e}$. His portfolio wealth for one period is then $W_{t}=W_{t-1}\left[w_{t} R_{t}^{h}+\left(1-w_{t}\right) R_{t}^{f}\right]$. The investor is assumed to maximize his expected utility function $E U\left(W_{t}\right)$.

In order to take into account the third moments, we consider a cubic Taylor expansion of expected utility around the average wealth ${ }^{30}$ :

$o^{(4)}$

$$
E\left(U\left(W_{t}\right)\right)=U\left(\overline{W_{t}}\right)+\frac{U^{\prime \prime}\left(\overline{W_{t}}\right)}{2} E\left(W_{t}-\overline{W_{t}}\right)^{2}+\frac{U^{\prime \prime \prime}\left(\overline{W_{t}}\right)}{3 !} E\left(W_{t}-\overline{W_{t}}\right)^{3}+
$$

where $\overline{W_{t}}=E\left(W_{t}\right)$, and $o^{(4)}$ represents the terms of order larger than three that are supposed to be negligible compared to the terms of smaller order. We also make the usual assumptions regarding the properties of the investor's utility function, that is positive marginal utility $\left(U^{\prime} \geq 0\right)$, risk aversion $\left(U^{\prime \prime} \leq 0\right)$, and non-increasing absolute risk aversion $\left(U^{\prime \prime \prime} \geq 0\right)$.

The third centered moment of the investor portfolio is given by:

$$
\begin{aligned}
E\left(W_{t}-\overline{W_{t}}\right)^{3}= & W_{t-1}^{3}\left[w_{t}^{3} \sigma_{h t}^{3} s_{h t}+\left(1-w_{t}\right)^{3} \sigma_{f t}^{3} s_{f t}\right. \\
& \left.+3 w_{t}^{2}\left(1-w_{t}\right) \sigma_{h t}^{2} \sigma_{f t} c_{h f t}+3 w_{t}\left(1-w_{t}\right)^{2} \sigma_{h t} \sigma_{f t}^{2} c_{f h t}\right]
\end{aligned}
$$

where

$$
\begin{aligned}
& \sigma_{i t}^{2}=\operatorname{var}\left(R_{t}^{i}\right) \\
& s_{i t}=E\left(\frac{R_{t}^{i}-E\left(R_{t}^{i}\right)}{\sigma_{i t}}\right)^{3} ; \\
& c_{i j t}=E\left(\left(\frac{R_{t}^{i}-E\left(R_{t}^{i}\right)}{\sigma_{i t}}\right)^{2}\left(\frac{R_{t}^{j}-E\left(R_{t}^{j}\right)}{\sigma_{j t}}\right)\right) .
\end{aligned}
$$

When a representative international investor has positive shares of foreign and domestic assets in his portfolio, skewness and co-skewness affect positively investor expected utility. Intuitively, when skewness (or co-skewness) decreases, the investor is less likely to diversify. In presence of negative skewness, investor will diversify less than he does for the MV portfolio which corresponds to a case of zero skewness. The results below formalize this intuition.

\subsection{Asymmetric Dependence and Cross-Country Portfolio Diversifica- tion: Home Bias Investment}

The importance of skewness in asset pricing and portfolio choice is well documented by Harvey and Siddique (2000) and the references therein. They find a negative trade-off

\footnotetext{
${ }^{30}$ Going back to Samuelson (1970), we can consider that a cubic expansion provides a reasonable approximation of the expected utility function, especially for distributions with low volatility.
} 
between expected returns and skewness. In a portfolio with a long position in two assets, co-skewness has a similar effect since it is positively related to the portfolio skewness. In a MV trade-off behavior, for a portfolio of two identically and independently distributed assets, we allocate one half of the portfolio to each asset. When the variance of one asset increases, its share decreases. The issue here is to investigate what is the effect of asymmetric dependence through co-skewness when we consider the third moment for expected utility.

To characterize asymmetric dependence, Longin and Solnik (2001) use exceedance correlation. This characterization does not allow us to make a link with the portfolio third moment. With the copula model we developed in the previous sections, it is possible to establish a link between co-skewness and asymmetric dependence.

Proposition 5.1: For $F$ and $F^{\prime}$ with the same marginal distributions and the same correlation coefficient, let $\left(X_{1}, X_{2}\right) \rightsquigarrow F \equiv\left(F_{1}, F_{2}, C_{r G}\right)$ and $\left(X_{1}^{\prime}, X_{2}^{\prime}\right) \rightsquigarrow F^{\prime} \equiv\left(F_{1}, F_{2}, C_{N}\right)$, where $C_{r G}$ is a rotated Gumbel copula and $C_{N}$ is a Gaussian copula such that $C_{N} \leq C_{r G}$. Therefore

$$
\left\{\begin{array}{l}
\operatorname{CoSkew}\left(X_{1}, X_{2}\right) \leq \operatorname{CoSkew}\left(X_{1}^{\prime}, X_{2}^{\prime}\right) \\
\operatorname{CoSkew}\left(X_{2}, X_{1}\right) \leq \operatorname{CoSkew}\left(X_{2}^{\prime}, X_{1}^{\prime}\right)
\end{array}\right.
$$

Proof See Appendix.

This result means that a strong dependence in lower returns creates a lower (or large negative) co-skewness. To analyze the effect of co-skewness on international diversification, we start from the MV optimal portfolio and then show that introducing skewness in the objective function, asymmetric dependence will reduce the portfolio share invested in the higher-risk assets for very risk averse investors.

Proposition 5.2: If the following conditions are satisfied

i) $\left|\sum_{n \geq 4:} \frac{1}{n !} U^{(n)}\left({\overline{W_{t}}}^{*}\right)\left[E\left(W_{t}^{*}-\bar{W}_{t}^{*}\right)^{n}\right]\right| \ll\left|\sum_{n=0:}^{3} \frac{1}{n !} U^{(n)}\left(\bar{W}_{t}^{*}\right)\left[E\left(W_{t}^{*}-\bar{W}_{t}^{*}\right)^{n}\right]\right|: v a-$ lidity of the third order approximation of expected utility around $\bar{W}_{t}^{*}$, the MV optimal portfolio final wealth

ii) the optimal share invested in domestic assets in a $M V$ behavior $w_{t}^{*}$ is in the range $(1 / 3,1)$, and is such that $\frac{\sigma_{f t}}{\sigma_{h t}}>\delta\left(w_{t}^{*}\right) \equiv \frac{w_{t}^{*}\left(2-3 w_{t}^{*}\right)}{\left(1-w_{t}^{*}\right)\left(3 w_{t}^{*}-1\right)}$ : large (perceived) risk for foreign portfolio.

iii) $c_{h f t}=c_{f h t} \equiv c_{t}$,

then there exists a threshold $\bar{c}_{t}$ such that for $c_{t} \leq \bar{c}_{t}$ we have

$$
\left.\frac{\partial}{\partial w_{t}} E U\left(W_{t}\right)\right|_{w_{t}=w_{t}^{*}}>0
$$


where $U^{(n)}$ is the n-order differential of $U$, and $U^{(0)}=U$.

Proof See Appendix

This proposition can be interpreted as follows. A strong downside market dependence which creates co-skewness combined with a large foreign risk implies that the share invested in the domestic portfolio will increase compared with the share invested in a MV framework. This provides an additional explanation for the home bias phenomenon. We may notice that the lower threshold $\delta($.$) for the ratio between foreign and domestic volatilities is a$ decreasing function of $w_{t}^{*}$, with $\delta(0.5)=1$. It means that if in the MV framework less than half of the wealth is invested in the domestic portfolio, foreign volatility should be greater than domestic volatility to insure that strong downside dependence will increase the home investment.

\subsection{Asymmetric Dependence Effect on Domestic Diversification: Flight to Safety.}

Starting at the MV optimal point, we can also perform a local analysis of the asymmetric dependence effect on the equity and bond diversification. Let $\eta_{t}^{h}\left(w_{t}^{*}, \eta_{t}^{f *}\right)$, the optimal share of bonds in the domestic portfolio, be a function of $w_{t}^{*}$, the MV optimal share invested in domestic assets, and $\eta_{t}^{f *}$, the MV optimal share of bonds in the foreign portfolio. As in the case of cross-country diversification, it can be similarly shown that asymmetric dependence will introduce a bond bias for a very risk averse investor. So, $\eta_{t}^{h}$ will increase in the asymmetric regime if its MV optimal solution $\eta_{t}^{h *}$ belong to the range $(1 / 3,1)$. A similar behavior will be observed for the share of bonds in the foreign portfolio.

The main intuition for the effect of asymmetric dependence on home bias is the increasing share invested in the asset with lower risk. The same intuition explains the fact that in the presence of asymmetric dependence, investors will increase the share of bonds in their portfolio relatively to equity. For less risk averse agents, the bond share is lower in the asymmetric framework than the share in the normal regime, but it becomes larger for investors with higher risk aversion. These results are related to the downside risk premium found by Ang et al (2006). Actually, diversification beyond a certain level increases downside risk and due to the trade-off between this risk and the expected return, investors should adjust their portfolio according to their risk aversion level. 


\section{Conclusion}

We have proposed a copula-based model of extreme dependence asymmetry that can rationalize the stylized facts put forward by Longin and Solnik. We applied it to the characterization of the dependence in the equity and bond markets of two pairs of countries, the United States and Canada and France and Germany respectively. We capture the wellknown strong asymmetric behavior across equity markets, but we also put forward a similar pattern in bond markets. The proposed model allowed us to discover a relationship between the filtered probabilities to be in the asymmetric regime and the volatility of exchange rates. This was not possible with the extreme value approach of Longin and Solnik (2001) since only the tails of the distributions are modeled.

We also derived the implications of the model for portfolio allocation. We show in particular under which conditions asymmetric extreme dependence will rationalize the phenomena known as home bias and flight to safety. Since the exchange rate volatility may be a factor behind the asymmetric behavior of international equity and bond market dependence, it will be interesting to extend the model to incorporate the exchange rate in order to study the portfolio of an international investor. Moreover, the asymmetry put forward between positive and negative extreme returns suggests to investigate the behavior of an investor endowed with disappointment aversion preferences as in Ang et al (2006). 


\section{Appendix A. Proofs}

\section{Proof of Proposition 2.1}

To prove this proposition, we need the two following lemmas

Lemma 1: (a) Let $\left\{f^{(s)}\right\}_{s=1}^{n}$ be a family of symmetric multivariate density functions of $n(\leq \infty)$ variables with same mean. The mixture $f=\sum_{s=1}^{n} \pi_{s} f^{(s)}$, where $\sum_{s=1}^{n} \pi_{s}=1$, and $\pi_{s} \geq 0$ for any $s$, is a symmetric multivariate density function. (b) Moreover for a continuum of symmetric multivariate density function $\left\{f^{(\sigma)}\right\}_{\sigma \in A \subseteq \mathbb{R}}$ with same mean, the mixture $f=\int_{A} \pi_{\sigma} f^{(\sigma)} d \sigma$, where $\int_{A} \pi_{\sigma} d \sigma=1$, is a symmetric multivariate density function.

Proof: Let $\mu$ be the mean of all $f^{(s)}$ (and all $f^{(\sigma)}$ )

$$
f(\mu-x)=\sum_{s=1}^{n} \pi_{s} f^{(s)}(\mu-x)
$$

by symmetry of all $f^{(s)}$, we have, $\sum_{s=1}^{n} \pi_{s} f^{(s)}(\mu-x)=\sum_{s=1}^{n} \pi_{s} f^{(s)}(\mu+x)=f(\mu+x)$

i.e. $f(\mu-x)=f(\mu+x)$ and the part (a) follows. Similarly for mixture of continuum, $f(\mu-x)=\int_{A} \pi_{\sigma} f^{(\sigma)}(\mu-x) d \sigma=\int_{A} \pi_{\sigma} f^{(\sigma)}(\mu+x) d \sigma=f(\mu+x)$ and we have (b).

Lemma 2: Let $\left\{F^{(s)}\right\}_{s=1}^{n}$ be a family of bivariate cdf with zero lower (upper) TDC. The mixture $F=\sum_{s=1}^{n} \pi_{s} F^{(s)}$, where $\sum_{s=1}^{n} \pi_{s}=1$, and $\pi_{s} \geq 0$, for any $s$, is a bivariate density function with lower (upper) TDC.

Proof: we do the proof for lower tail since by "rotation" we have the same result for upper tail.

Let $\tau_{L}^{F}$ be the lower TDC of $F$, we have

$$
\begin{aligned}
\tau_{L}^{F} & =\lim _{\alpha \rightarrow 0} \operatorname{Pr}\left[X \leq F_{x}^{-1}(\alpha) \mid Y \leq F_{y}^{-1}(\alpha)\right] \\
& =\lim _{\alpha \rightarrow 0} \frac{\operatorname{Pr}\left[X \leq F_{x}^{-1}(\alpha), Y \leq F_{y}^{-1}(\alpha)\right]}{\operatorname{Pr}\left[Y \leq F_{y}^{-1}(\alpha)\right]} \\
& =\lim _{\alpha \rightarrow 0} \frac{F\left(F_{x}^{-1}(\alpha), F_{y}^{-1}(\alpha)\right)}{F_{y}\left(F_{y}^{-1}(\alpha)\right)}
\end{aligned}
$$

and since $F=\sum_{s=1}^{n} \pi_{s} F^{(s)}$, we have 


$$
\begin{aligned}
\tau_{L}^{F} & =\lim _{\alpha \rightarrow 0} \frac{\sum_{s=1}^{n} \pi_{s} F^{(s)}\left(F_{x}^{-1}(\alpha), F_{y}^{-1}(\alpha)\right)}{\alpha} \\
& =\lim _{\alpha \rightarrow 0} \sum_{s=1}^{n} \pi_{s} \frac{F^{(s)}\left(F_{x}^{-1}(\alpha), F_{y}^{-1}(\alpha)\right)}{\alpha} \\
& =\sum_{s=1}^{n} \pi_{s} \lim _{\alpha \rightarrow 0} \frac{F^{(s)}\left(F_{x}^{-1}(\alpha), F_{y}^{-1}(\alpha)\right)}{\alpha}
\end{aligned}
$$

by definition $F^{(s)}\left(F_{x}^{-1}(\alpha), F_{y}^{-1}(\alpha)\right)=C^{(s)}\left(F_{x}^{(s)}\left(F_{x}^{-1}(\alpha)\right), F_{y}^{(s)}\left(F_{y}^{-1}(\alpha)\right)\right)$

where $C^{(s)}$ is the copula and $F_{x}^{(s)}, F_{y}^{(s)}$ the marginal cdf corresponding to $F^{(s)}$, we have

$$
\alpha=F_{x}\left(F_{x}^{-1}(\alpha)\right)=\sum_{s=1}^{n} \pi_{s} F_{x}^{(s)}\left(F_{x}^{-1}(\alpha)\right)
$$

so

$F_{x}^{(s)}\left(F_{x}^{-1}(\alpha)\right) \leq \alpha / \pi_{s}$ for all $s$ and similarly $F_{y}^{(s)}\left(F_{y}^{-1}(\alpha)\right) \leq \alpha / \pi_{s}$,

hence

$$
\begin{aligned}
\lim _{\alpha \rightarrow 0} \frac{F^{(s)}\left(F_{x}^{-1}(\alpha), F_{y}^{-1}(\alpha)\right)}{\alpha} & =\lim _{\alpha \rightarrow 0} \frac{C^{(s)}\left(F_{x}^{(s)}\left(F_{x}^{-1}(\alpha)\right), F_{y}^{(s)}\left(F_{y}^{-1}(\alpha)\right)\right)}{\alpha} \\
& \leq \lim _{\alpha \rightarrow 0} \frac{C^{(s)}\left(\alpha / \pi_{s}, \alpha / \pi_{s}\right)}{\alpha}, \text { since copula is increasing function } \\
& =1 / \pi_{s} \lim _{\alpha^{\prime} \rightarrow 0} \frac{C^{(s)}\left(\alpha^{\prime}, \alpha^{\prime}\right)}{\alpha^{\prime}} \text { by setting } \alpha^{\prime}=\alpha / \pi_{s} \\
& =0, \text { since } F^{(s)} \text { and hence } C^{(s)} \text { is zero lower TDC }
\end{aligned}
$$

we therefore have $\tau_{L}^{F}=0$

The part (i) and (ii) of the proposition is the straightforward application of above lemma

- For GARCH with constant mean and symmetric conditional distribution

$$
X_{t}=\mu+\Sigma_{t-1}^{1 / 2} \varepsilon_{t}
$$

$$
\left(+ \text { any GARCH dynamic equation of } \Sigma_{t-1}\right)
$$

where $\varepsilon_{t}$ is stationary with symmetric distribution such that $E\left(\varepsilon_{t}\right)=0$. The unconditional distribution of $X_{t}$ is a mixture of distribution of symmetric variable with same mean $\mu$ but possibly different variance covariance matrix. By applying the lemma 1, we conclude that the unconditional distribution of $X_{t}$ is symmetric and (i) follows. 
- For RS model with zero TDC

$$
X_{t}=\mu_{s_{t}}+\Sigma_{s_{t}}^{1 / 2} \varepsilon_{t}
$$

where $s_{t}$ takes a discrete value. Without loss of generality assume that $X_{t}$ is bivariate and that $s_{t}=s, \mu+\Sigma^{1 / 2} \varepsilon_{t}$ is zero TDC such as in the normal case, therefore the unconditional distribution of $X_{t}$ is a mixture of distribution with zero TDC. By applying the lemma 2, we conclude that the unconditional distribution of $X_{t}$ has zero TDC. and (ii) follows

For (iii), with the same notations as lemma 1, keeping marginal distribution unchanged across mixture components means that. For discrete case

$$
\begin{aligned}
f^{(s)}\left(x_{1}, \ldots, x_{n} ; \delta, \rho\right)=c^{(s)}\left(u_{1}, \ldots, u_{n} ; \theta\right) \times \prod_{i=1}^{n} f_{i}\left(x_{i} ; \delta_{i}\right), \text { with } u_{i}=F_{i}\left(x_{i} ; \delta_{i}\right), \text { hence } \\
\begin{aligned}
f\left(x_{1}, \ldots, x_{n} ; \delta, \rho\right) & =\sum_{s=1}^{n} \pi_{s} f^{(s)}\left(x_{1}, \ldots, x_{n} ; \delta, \rho\right) \\
& =\sum_{s=1}^{n} \pi_{s} c^{(s)}\left(u_{1}, \ldots, u_{n} ; \theta\right) \times \prod_{i=1}^{n} f_{i}\left(x_{i} ; \delta_{i}\right) \\
& =c\left(u_{1}, \ldots, u_{n} ; \theta\right) \times \prod_{i=1}^{n} f_{i}\left(x_{i} ; \delta_{i}\right)
\end{aligned}
\end{aligned}
$$

with $c\left(u_{1}, \ldots, u_{n} ; \theta\right)=\sum_{s=1}^{n} \pi_{s} c^{(s)}\left(u_{1}, \ldots, u_{n} ; \theta\right)$ is the copula of $f$ and we can see that $c$ is a mixture of copula with symmetric TDC and hence is a copula with symmetric TDC.

for the continuum case

$$
\begin{aligned}
f\left(x_{1}, \ldots, x_{n} ; \delta, \rho\right) & =\int_{A} \pi_{\sigma} f^{(\sigma)}\left(x_{1}, \ldots, x_{n} ; \delta, \rho\right) d \sigma \\
& =\int_{A} \pi_{\sigma} c^{(\sigma)}\left(u_{1}, \ldots, u_{n} ; \theta\right) d \sigma \times \prod_{i=1}^{n} f_{i}\left(x_{i} ; \delta_{i}\right) \\
& =c\left(u_{1}, \ldots, u_{n} ; \theta\right) \times \prod_{i=1}^{n} f_{i}\left(x_{i} ; \delta_{i}\right)
\end{aligned}
$$

with $c\left(u_{1}, \ldots, u_{n} ; \theta\right)=\int_{A} \pi_{\sigma} c^{(\sigma)}\left(u_{1}, \ldots, u_{n} ; \theta\right) d \sigma$ which is a copula with symmetric TDC for same the reasons mentioned above.

Q.E.D

\section{Proof of Proposition 3.2.}

By definition of a copula, we have 


$$
\begin{aligned}
\eta_{t} & =\left[\begin{array}{l}
f\left(X_{t} ; \delta, \theta \mid \underline{X}_{t-1}, s_{t}=1\right) \\
f\left(X_{t} ; \delta, \theta \mid \underline{X}_{t-1}, s_{t}=0\right)
\end{array}\right] \\
& =\left[\begin{array}{l}
c\left(u_{1, t}\left(\delta_{1}\right), \ldots, u_{4, t}\left(\delta_{4}\right) ; \theta \mid s_{t}=1\right) \times \prod_{i=1}^{4} f_{i}\left(x_{i, t} ; \delta_{i}\right) \\
c\left(u_{1, t}\left(\delta_{1}\right), \ldots, u_{4, t}\left(\delta_{4}\right) ; \theta \mid s_{t}=0\right) \times \prod_{i=1}^{4} f_{i}\left(x_{i, t} ; \delta_{i}\right)
\end{array}\right]
\end{aligned}
$$

with $u_{i, t}\left(\delta_{i}\right)=F_{i}\left(x_{i, t} ; \delta_{i}\right)$

By denoting $\widehat{\xi}_{t \mid t-1}=\left(\widehat{\xi}_{t \mid t-1}^{(1)}, \widehat{\xi}_{t \mid t-1}^{(0)}\right)^{\prime}$, the likelihood can be rewritten

$$
\begin{aligned}
& L\left(\delta, \theta ; \underline{X}_{T}\right) \\
& =\sum_{t=1}^{T} \log \left(\widehat{\xi}_{t \mid t-1}^{\prime} \eta_{t}\right) \\
& =\sum_{t=1}^{T} \log \left(\sum_{k=0}^{1} \widehat{\xi}_{t \mid t-1}^{(k)} c\left(u_{1, t}\left(\delta_{1}\right), \ldots, u_{4, t}\left(\delta_{4}\right) ; \theta \mid s_{t}=k\right) \times \prod_{i=1}^{4} f_{i}\left(x_{i, t} ; \delta_{i}\right)\right) \\
& \left.=\sum_{t=1}^{T}\left[\sum_{i=1}^{4} \log \left(f_{i}\left(x_{i, t} ; \delta_{i}\right)\right)\right)+\log \left(\sum_{k=0}^{1} \widehat{\xi}_{t \mid t-1}^{(k)} c\left(u_{1, t}\left(\delta_{1}\right), \ldots, u_{4, t}\left(\delta_{4}\right) ; \theta \mid s_{t}=k\right)\right)\right]
\end{aligned}
$$

it follows that

$$
L\left(\delta, \theta ; \underline{X}_{T}\right)=\sum_{i=1}^{4} L_{i}\left(\delta_{i} ; \underline{X}_{T}\right)+L_{C}\left(\delta, \theta ; \underline{X}_{T}\right)
$$

where

$$
\begin{aligned}
& L_{i}\left(\delta_{i} ; \underline{X}_{i, T}\right)=\sum_{t=1}^{T} \log f_{i}\left(x_{i, t} ; \delta_{i} \mid \underline{X}_{i, t-1}\right) \\
& L_{C}(\delta, \theta ; X)=\sum_{t=1}^{T} \log \left(\widehat{\xi}_{t \mid t-1}^{\prime} \eta_{c t}\right)
\end{aligned}
$$

with

$$
\eta_{c t}=\left[\begin{array}{c}
c\left(u_{1, t}\left(\delta_{1}\right), \ldots, u_{n, t}\left(\delta_{n}\right) ; \theta \mid s_{t}=1\right) \\
c\left(u_{1, t}\left(\delta_{1}\right), \ldots, u_{n, t}\left(\delta_{n}\right) ; \theta \mid s_{t}=0\right)
\end{array}\right]
$$

by noticing that $\eta_{t}=\eta_{c t} \times \prod_{i=1}^{4} f_{i}\left(x_{i, t} ; \delta_{i}\right)$ we have that

$$
\widehat{\xi}_{t / t}=\left[\widehat{\xi}_{t \mid t-1}^{\prime} \eta_{t}\right]^{-1}\left(\widehat{\xi}_{t \mid t-1} \odot \eta_{t}\right)=\left[\widehat{\xi}_{t \mid t-1}^{\prime} \eta_{c t}\right]^{-1}\left(\widehat{\xi}_{t \mid t-1} \odot \eta_{c t}\right)
$$

Q.E.D

\section{Proof of proposition 5.1}

Let $\left(X_{1}, X_{2}\right) \rightsquigarrow F \equiv\left(F_{1}, F_{2}, C_{r G}\right)$ and $\left(X_{1}^{\prime}, X_{2}^{\prime}\right) \rightsquigarrow F^{\prime} \equiv\left(F_{1}, F_{2}, C_{N}\right)$.

for $w \in[0,1]$ let $X=w X_{1}+(1-w) X_{2}$, and $X^{\prime}=w X_{1}^{\prime}+(1-w) X_{2}^{\prime}$ 


$$
E(U(X))=U(\bar{X})+\frac{U^{\prime \prime}(\bar{X})}{2} E(X-\bar{X})^{2}+\frac{U^{\prime \prime \prime}(\bar{X})}{3} E(X-\bar{X})^{3}+o^{(4)}
$$

and $E\left(X^{\prime}\right)=E(X)=\bar{X}$, we have

$$
E\left(U\left(X^{\prime}\right)\right)=U(\bar{X})+\frac{U^{\prime \prime}(\bar{X})}{2} E\left(X^{\prime}-\bar{X}\right)^{2}+\frac{U^{\prime \prime \prime}(\bar{X})}{3} E\left(X^{\prime}-\bar{X}\right)^{3}+o^{(4)}
$$

by assumption, we have $C_{N} \leq C_{r G}$ what by the below lemma, is equivalent to $F^{\prime} \leq F$, and then $E\left(U\left(X^{\prime}\right)\right) \geq E(U(X))$ for any increasing function $U$. So for an utility function $U$ that satisfies Arrow (1971) third main desirable property $U^{\prime \prime \prime} \geq 0$, we have $E\left(X^{\prime}-\bar{X}\right)^{3} \geq$ $E(X-\bar{X})^{3}$.

Since for any $w \in[0,1]$

$$
\begin{aligned}
E(X-\bar{X})^{3}= & w^{3} \sigma_{1}^{3} s_{1}+(1-w)^{3} \sigma_{2}^{3} s_{2} \\
& +3 w^{2}(1-w) \sigma_{1}^{2} \sigma_{2} c_{12}+3 w(1-w)^{2} \sigma_{1} \sigma_{2}^{2} c_{21}
\end{aligned}
$$

and

$$
\begin{aligned}
E\left(X^{\prime}-\bar{X}\right)^{3}= & w^{3} \sigma_{1}^{3} s_{1}+(1-w)^{3} \sigma_{2}^{3} s_{2} \\
& +3 w^{2}(1-w) \sigma_{1}^{2} \sigma_{2} c_{12}^{\prime}+3 w(1-w)^{2} \sigma_{1} \sigma_{2}^{2} c_{21}^{\prime}
\end{aligned}
$$

we have

$$
\left\{\begin{array}{l}
c_{12} \leq c_{12}^{\prime} \\
c_{21} \leq c_{21}^{\prime}
\end{array}\right.
$$

i.e.

$$
\left\{\begin{array}{l}
\operatorname{CoSkew}\left(X_{1}, X_{2}\right) \leq \operatorname{CoSkew}\left(X_{1}^{\prime}, X_{2}^{\prime}\right) \\
\operatorname{CoSkew}\left(X_{2}, X_{1}\right) \leq \operatorname{CoSkew}\left(X_{2}^{\prime}, X_{1}^{\prime}\right)
\end{array}\right.
$$

Q.E.D

Lemma: Let $F \equiv\left(F_{1}, F_{2}, C\right)$ and $\left(X_{1}^{\prime}, X_{2}^{\prime}\right) \rightsquigarrow F^{\prime} \equiv\left(F_{1}, F_{2}, C^{\prime}\right)$.

$C^{\prime} \leq C$ is equivalent to $F^{\prime} \leq F$.

\section{Proof}

$$
\begin{aligned}
& F^{\prime} \leq F \\
& \Leftrightarrow F^{\prime}(x, y) \leq F(x, y) \text { for all }(x, y) \in \mathbb{R}^{2} \\
& \Leftrightarrow C\left(F_{1}(x), F_{2}(y)\right) \leq C^{\prime}\left(F_{1}(x), F_{2}(y)\right) \text { for all }(x, y) \in \mathbb{R}^{2} \\
& \Leftrightarrow C(u, v) \leq C^{\prime}(u, v) \text { for all }(u, v) \in[0,1]^{2} \\
& \Leftrightarrow C^{\prime} \leq C .
\end{aligned}
$$

Q.E.D

\section{Proof of Proposition 5.2:}


The exact expansion of the expected utility function is $E U\left(W_{t}\right)=\sum_{n=0}^{\infty} \frac{1}{n !} U^{(n)}\left(\overline{W_{t}}\right) E\left(W_{t}-\bar{W}_{t}\right)^{(n)}$. Under assumption $i$ ), and the third order validity of the Taylor expansion, the sign of $\left.\frac{\partial}{\partial w} E U\left(W_{t}\right)\right|_{w_{t}=w_{t}^{*}}$ depends on the sign of $\left.\frac{\partial}{\partial w_{t}} U^{\prime \prime \prime}\left(\bar{W}_{t}\right) E\left(W_{t}-\bar{W}_{t}\right)^{3}\right|_{w_{t}=w_{t}^{*}}$ since saying that $w_{t}^{*}$ is the optimal part invested on home portfolio in a Mean-Variance behavior means that

$$
\left.\frac{\partial}{\partial w_{t}}\left\{U\left(\overline{W_{t}}\right)+\frac{U^{\prime \prime}\left(\bar{W}_{t}\right)}{2} E\left(W_{t}-\bar{W}_{t}\right)^{2}\right\}\right|_{w_{t}=w_{t}^{*}}=0 .
$$

and

$$
\begin{aligned}
\left.\frac{\partial}{\partial w_{t}} U^{\prime \prime \prime}\left(\bar{W}_{t}\right) E\left(W_{t}-\bar{W}_{t}\right)^{3}\right|_{w_{t}=w_{t}^{*}}= & {\left.\left[\frac{\partial}{\partial w_{t}} U^{\prime \prime \prime}\left(\bar{W}_{t}\right)\right]\right|_{w_{t}=w_{t}^{*}} E\left(W_{t}^{*}-\bar{W}_{t}^{*}\right)^{3} } \\
& +\left.U^{\prime \prime \prime}\left(\bar{W}_{t}^{*}\right) \frac{\partial}{\partial w_{t}} E\left(W_{t}-\bar{W}_{t}\right)^{3}\right|_{w_{t}=w_{t}^{*}}
\end{aligned}
$$

we have

$$
\begin{aligned}
\left.\frac{\partial}{\partial w_{t}} E\left(W_{t}-\bar{W}_{t}\right)^{3}\right|_{w_{t}=w_{t}^{*}}= & 3 w_{t}^{* 2} \sigma_{h t}^{3} s_{h t}-3\left(1-w_{t}^{*}\right)^{2} \sigma_{f t}^{3} s_{f t} \\
& +3\left(2 w_{t}^{*}-3 w_{t}^{* 2}\right) \sigma_{h t}^{2} \sigma_{f t} c_{12 t}+3\left(1-4 w_{t}^{*}+3 w_{t}^{* 2}\right) \sigma_{h t} \sigma_{f t}^{2} c_{21 t} \\
= & 3 w_{t}^{* 2} \sigma_{h t}^{3} s_{h t}-3\left(1-w_{t}^{*}\right)^{2} \sigma_{f t}^{3} s_{f t} \\
& +\left[3\left(2 w_{t}^{*}-3 w_{t}^{* 2}\right) \sigma_{h t}^{2} \sigma_{f t}+3\left(1-4 w_{t}^{*}+3 w_{t}^{* 2}\right) \sigma_{h t} \sigma_{f t}^{2}\right] c_{t} \\
= & B_{t}+A_{t} c_{t}
\end{aligned}
$$

with

$$
\left\{\begin{array}{l}
B_{t}=3\left[w_{t}^{* 2} \sigma_{h t}^{3} s_{h t}-\left(1-w_{t}^{*}\right)^{2} \sigma_{f t}^{3} s_{f t}\right] \\
A_{t}=3\left[\left(2 w_{t}^{*}-3 w_{t}^{* 2}\right) \sigma_{h t}^{2} \sigma_{f t}+\left(1-4 w_{t}^{*}+3 w_{t}^{* 2}\right) \sigma_{h t} \sigma_{f t}^{2}\right]
\end{array}\right.
$$

by assumptions ii) $A_{t}<0$ and by taking

$$
\bar{c}_{t}=\left[\left.\left[\frac{\partial}{\partial w_{t}} U^{\prime \prime \prime}\left(\bar{W}_{t}\right)\right]\right|_{w_{t}=w_{t}^{*}} \frac{E\left(W_{t}^{*}-\bar{W}_{t}^{*}\right)^{3}}{U^{\prime \prime \prime}\left(\bar{W}_{t}^{*}\right)}-B_{t}\right] / A_{t},
$$

for $c_{t} \leq \bar{c}_{t}$, we have $\left.\frac{\partial}{\partial w_{t}} U^{\prime \prime \prime}\left(\bar{W}_{t}\right) E\left(W_{t}-\bar{W}_{t}\right)^{3}\right|_{w_{t}=w_{t}^{*}}>0$, and the proposition 2 follows.

Q.E.D 


\section{Appendix B. Analytical expressions for various copulas}

\section{Normal copula}

$C_{N}\left(u_{1}, \ldots, u_{n} ; \rho\right)=\Phi_{\rho}\left(\Phi^{-1}\left(u_{1}\right), \ldots, \Phi^{-1}\left(u_{n}\right)\right)$

$C_{N}\left(u_{1}, \ldots, u_{n} ; \rho\right)=\int_{-\infty}^{\Phi^{-1}\left(u_{1}\right)} \ldots \int_{-\infty}^{\Phi^{-1}\left(u_{n}\right)}\left[(2 \pi)^{n} \operatorname{det}(\rho)\right]^{-\frac{1}{2}} \exp \left[-\frac{1}{2}\left(z^{\prime} \rho^{-1} z\right)\right] d z_{1} \ldots d z_{n}$

where $z=\left(z_{1}, \ldots, z_{n}\right)^{\prime}, \rho=\left(\rho_{i j}\right)_{i, j=1}^{n}$, with $\left|\rho_{i j}\right| \leq 1, \rho_{i i}=1$ and $\rho$ positive defined matrix

$c_{N}\left(u_{1}, \ldots, u_{n} ; \rho\right)=\left(\operatorname{det}(\rho) \exp \left[x^{\prime} \rho^{-1} x-x^{\prime} x\right]\right)^{-1 / 2}$

with $x=\left(\Phi^{-1}\left(u_{1}\right), \ldots, \Phi^{-1}\left(u_{n}\right)\right)^{\prime}$,

$\Phi$ is $c d f$ of standard normal distribution and $\Phi_{\rho}$ is $c d f$ of multivariate normal distribution with correlation matrix $\rho$.

Tail dependence coefficients are

$\tau^{L}=\tau^{U}=0$

\section{Bivariate Gumbel copula}

$$
\begin{aligned}
& C_{G}(u, v ; \theta)=\exp \left[-\left((-\log (u))^{\theta}+(-\log (v))^{\theta}\right)^{1 / \theta}\right] \\
& c_{G}(u, v ; \theta)=\frac{C_{G}(u, v ; \theta)(\log (u) \cdot \log (v))^{\theta-1}}{u v\left((-\log (u))^{\theta}+(-\log (v))^{\theta}\right)^{2-1 / \theta}}\left(\left((-\log (u))^{\theta}+(-\log (v))^{\theta}\right)^{1 / \theta}+\theta-1\right)
\end{aligned}
$$

\section{Bivariate Rotated Gumbel (Survival) copula}

$C_{G S}(u, v ; \theta)=u+v-1+C_{G}(1-u, 1-v ; \theta)$

$c_{G S}(u, v ; \theta)=c_{G}(1-u, 1-v ; \theta)$

The tail dependence coefficients of $C_{G S}$ are

$$
\begin{gathered}
\tau^{L}=2-2^{\frac{1}{\theta}} \text { and } \tau^{U}=0 \\
\text { so } \theta=\theta\left(\tau^{L}\right)=\frac{\log (2)}{\log \left(2-\tau^{L}\right)}
\end{gathered}
$$

and we can re-parameterize the Copula $C_{G S}(u, v ; \theta)$ with $\tau^{L}$ as $C_{G S}\left(u, v ; \tau^{L}\right)=C_{G S}\left(u, v ; \theta\left(\tau^{L}\right)\right)$ 


\section{References}

[1] Aas, K., C. Czado, A. Frigessi, and H. Bakken (2007), "Pair-copula constructions of multiple dependence", Insurance: Mathematics and Economics, 44, 182-198

[2] Andrews, D. W. K. (2001), "Testing when the Parameter is on the Boundary of the Maintained Hypothesis", Econometrica 69, 683-734.

[3] Andrews, D. W. K. and W. Ploberger (1994), "Optimal Tests when a Nuisance Parameter is Present Only Under the Alternative", Econometrica, 62 1383-1414.

[4] Ang, A. and G. Bekaert (2002), "International Asset Allocation with Regime Shifts", Review of Financial Studies, 11, 1137-1187.

[5] Ang, A. and G. Bekaert (2004), "How do Regimes Affect Asset Allocation?", Financial Analysts Journal, 60, 2, 86-99.

[6] Ang, A. and J. Chen (2002), "Asymmetric Correlations of Equity Portfolios", Journal of Financial Economics, 63, 443-494.

[7] Ang, A., J. Chen and Y. Xing (2006), "Downside Risk", Review of Financial Studies, 19, 1191-1239.

[8] Arrow, K. (1971), Essay in the theory of risk bearing, Chicago: Markham Publishing Co.

[9] Barnard, G. A. (1963), "Comment on "The spectral analysis of point processes" by M. S. Bartlett", Journal of the Royal Statistical Society, Series B 25, 294.

[10] Bollerslev, T. (1986), "Generalized Autoregressive Conditional Heteroskedasticity", Journal of Econometrics, 31, 307-327.

[11] Bollerslev, T. (1990), "Modelling the Coherence in Short-Run Nominal Exchange Rates: A Multivariate Generalized ARCH Model", Review of Economics and Statistics, $31,307-327$.

[12] Bontemps, C. and N. Meddahi (2005), "Testing Normality: A GMM Approach", Journal of Econometrics, 124, 149-186.

[13] Boyer, B. H., M. S. Gibson and M. Loretan (1999), "Pitfalls in tests for changes in correlations", International Finance Discussion Paper 597, Board of the Governors of the Federal Reserve System. 
[14] Cappiello, L., R. F. Engle and K. Sheppard (2003), "Asymmetric Dynamics in the Correlations of Global Equity and Bond Returns", Forthcoming, Journal of Financial Econometrics.

[15] Chen, X., Y. Fan and A. Patton (2004), "Simple Tests for Models of Dependence Between Multiple Financial Time Series, with Applications to U.S. Equity Returns and Exchange Rates", working paper, London School of Economics.

[16] Das, S., and R. Uppal, (2003), "Systemic risk and international portfolio choice" Journal of Finance, Forthcoming.

[17] Denuit, M. and O. Scaillet (2004) "Nonparametric Tests for Positive Quadrant Dependence", Journal of Financial Econometrics, 2, 422-450.

[18] Dufour J. M. (2005) "Monte Carlo Tests with Nuisance Parameters: A General Approach to Finite-Sample Inference and Nonstandard Asymptotics", Journal of Econometrics, Forthcoming.

[19] Dwass, M. (1957), "Modified randomization tests for nonparametric hypotheses", Annals of Mathematical Statistics 28, 181-187.

[20] Engle, R. F. (1982) "Autoregressive Conditional Heteroskedasticity Models with estimation of Variance of United Kingdom Inflation", Econometrica, 50, 987-1007.

[21] Engle, R. F. (2002), "Dynamic Conditional Correlation: A Simple Class of Multivariate Generalized Autoregressive Conditional Heteroskedasticity Models", Journal of Business and Economic Statistics, 20, 339-350.

[22] Engle, R. F and K. Kroner (1995), "Multivariate Simultaneous Generalized ARCH", Econometric Theory, 11, 122-150.

[23] Erb, C., C. Harvey and T. Viskanta (1994), "Forecasting international equity correlations", Financial Analysts Journal 50, 32-45.

[24] Forbes, K. J. and R. Rigobon (2002), "No contagion, only interdependence: measuring stock market comovements", Journal of Finance, 57, 2223-2261.

[25] Friend, I. and R. Westerfield (1980) "Co-skewnes and Capital Asset Pricing", Journal of Finance, 35, 897-913. 
[26] Garcia, R. (1998), "Asymptotic Null Distribution of the Likelihood Ratio Test in Markov Switching Models", International Economic Review, 39, 763-788.

[27] Genest, C., J. J. Q. Molina and J. A. R. Lallena (1995), "De l'impossibilité de construire des lois à marges multidimensionnelles données à partir des copules", C. R. Acad. Sci. Paris Sér. I Math. 320, 723-726.

[28] Genest, C. and L. P. Rivest (1993), "Statiscal Inference Procedures for Bivariate Archimedean Copulas" Journal of American Statistical Association, 88, 1034-1043.

[29] Glassman, D. A., and L. A. Riddick (2001), "What causes home asset bias and how should it be measured", Journal of Empirical Finance 8, 35-54.

[30] Guidolin, M. and A., Timmermann, (2006), "International Asset Allocation under Regime Switching, Skew and Kurtosis Preferences "Working Paper, Federal Reserve of St-Louis.

[31] Hamilton, J. D. (1989), "A New Approach to the Economic Analysis of Nonstationary Time Series and the Business Cycle", Econometrica, 57, 357-384.

[32] Hamilton, J. D. (1994), Time Series Analysis,. Princeton University Press.

[33] Hansen, B. E. (1992), "The Likelihood Ratio Test Under Nonstandard Conditions: Testing the Markov Switching Model of GNP", Journal of Applied Econometrics, 7, S61-S82.

[34] Hansen, B. E. (1996), "Inference When a nuisance Parameter Is not Identified Under the Null Hypothesis", Econometrica, 64, 413-430.

[35] Hartmann, P., S. Straeman, and C. De Vries (2004), "Asset Market Linkages in Crisis Periods", Review of Economics and Statistics, 86, 313-326

[36] Harvey, C., and A. Siddique (2000) "Conditional Skewness in Asset Pricing Tests", Journal of Finance, 55, 1263-1296.

[37] Heston, S. and S. Nandi (2000), "A Closed-Form GARCH Option Valuation Model", Review of Financial Studies, 13, 585-625.

[38] Jondeau, E. and M. Rockinger (2006), "The Copula-GARCH Model of Conditional Dependencies: An International Stock-Market Application", Journal of International Money and Finance, 25, 5, 827-853. 
[39] Kraus, A. and R. H. Litzenberger (1976) "Skewness Preference and The Valuation of Risk Assets", Journal of Finance, 31, 1085-1100.

[40] Longin, F. and B. Solnik (2001), "Extreme correlations in international Equity Markets", Journal of Finance, 56, 649-676.

[41] Nelsen, R. B. (1998), An Introduction to copula, Springer-Verlag, New York.

[42] Patton, A. (2004), "On the Out-of-Sample Importance of Skewness and Asymmetric Dependence for Asset Allocation", Journal of Financial Econometrics, 2, 130-168.

[43] Pelletier, D. (2004), "Regime Switching for Dynamic Correlations", Journal of Econometrics, Forthcoming.

[44] Perold, A.F. and E.R. Sirri (1994), "The Cost of International Equity Trading", Unpublished manuscript.

[45] Rodriguez, J. C. (2007), "Measuring Financial Contagion: A Copula Approach", Journal of Empirical Finance, 14, 3, 401-423.

[46] Samuelson, P. A. (1970) "The Fundamental Approximation Theorem of Portfolio Analysis in terms of Means, Variances and Higher Moments", Review of Economics Studies, 37, 537-542.

[47] Sklar, A. (1959), "Fonctions de répartition à n dimensions et leurs marges", Publications de l'Institut de Statistique de l'Université de Paris, 8, 229-231.

[48] Solnik, B., 1996. International Investments. 3rd edn. Addison-Wesley Publishing, Reading, MA. 
Table 1: Summary statistics of weekly bond and equity index returns for the four countries. All returns are in US dollars, from January 01, 1985 to December 21, 2004, which corresponds to a sample of 1044 observations. ( ${ }^{\delta}$ denotes annualized percent). Sharpe ratio represents the ratio of the mean over the standard deviation of return.

\begin{tabular}{lccccccc}
\hline \hline & Mean $^{\delta}$ & Std $^{\delta}$ & Kurtosis & Skewness & Min $^{\delta}$ & Max $^{\delta}$ & Sharpe ratio \\
\hline US Equity & 13.67 & 17.51 & 17.00 & -1.55 & -680.36 & 311.10 & 0.78 \\
US Bond & 7.57 & 4.69 & 0.67 & -0.06 & -66.91 & 58.81 & 1.61 \\
CA Equity & 11.24 & 16.72 & 13.62 & -1.67 & -610.87 & 225.15 & 0.67 \\
CA Bond & 8.81 & 8.15 & 1.13 & -0.24 & -130.55 & 118.07 & 1.08 \\
FR Equity & 14.72 & 23.43 & 7.18 & -0.09 & -582.12 & 512.16 & 0.63 \\
FR Bond & 11.52 & 11.16 & 0.92 & 0.04 & -142.02 & 166.68 & 1.03 \\
DE Equity & 12.57 & 24.97 & 8.01 & -0.46 & -574.96 & 463.08 & 0.50 \\
DE Bond & 10.44 & 11.56 & 0.82 & -0.01 & -142.54 & 171.39 & 0.90 \\
\hline \hline
\end{tabular}

Table 2: Unconditional correlations between bonds and equity for US, Canada (CA), France (FR) and Germany (DE).

\begin{tabular}{lccccccc}
\hline \hline & US & US & CA & CA & FR & FR & DE \\
& Equity & Bond & Equity & Bond & Equity & Bond & \begin{tabular}{c} 
Equity \\
\hline US Bond
\end{tabular} \\
0.0576 & & & & & & \\
CA Equity & 0.7182 & 0.0116 & & & & & \\
CA Bond & 0.1783 & 0.4706 & 0.4392 & & & & \\
FR Equity & 0.1957 & -0.0182 & 0.1974 & 0.1065 & & & \\
FR Bond & -0.0499 & 0.3386 & -0.0080 & 0.2433 & 0.3066 & & \\
DE Equity & 0.2089 & -0.0536 & 0.1995 & 0.1009 & 0.8099 & 0.2625 & \\
DE Bond & -0.0832 & 0.3081 & -0.0234 & 0.2143 & 0.3084 & 0.9403 & 0.2847 \\
\hline \hline
\end{tabular}


Table 3: Estimates of M-GARCH $(1,1)$ parameters for all bond and equity returns of four countries. The figures between brackets represent standard deviations of the parameters. $L$ is the value of the $\log$-likelihood function.

\begin{tabular}{|c|c|c|c|c|c|c|c|c|}
\hline & \multicolumn{2}{|c|}{ 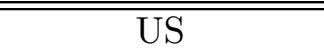 } & \multicolumn{2}{|c|}{$\mathrm{CA}$} & \multicolumn{2}{|c|}{ FR } & \multicolumn{2}{|c|}{$\mathrm{DE}$} \\
\hline & Equity & Bond & Equity & Bond & Equity & Bond & Equity & Bond \\
\hline \multirow[t]{2}{*}{$\beta$} & $7.94 \mathrm{e}-1$ & $7.82 \mathrm{e}-1$ & $8.09 \mathrm{e}-1$ & $9.07 \mathrm{e}-1$ & $9.68 \mathrm{e}-1$ & $9.36 \mathrm{e}-1$ & $9.24 \mathrm{e}-1$ & $9.56 \mathrm{e}-1$ \\
\hline & $(3.49 \mathrm{e}-1)$ & $(1.62 \mathrm{e}-1)$ & $(4.06 \mathrm{e}-1)$ & $(1.79 \mathrm{e}-1)$ & $(3.61 \mathrm{e}-1)$ & $(4.21 \mathrm{e}-1)$ & $(1.54 \mathrm{e}-1)$ & $(2.45 \mathrm{e}-1)$ \\
\hline \multirow[t]{2}{*}{$\alpha$} & $5.46 \mathrm{e}-5$ & $2.63 \mathrm{e}-6$ & $6.40 \mathrm{e}-5$ & $7.30 \mathrm{e}-6$ & $2.28 \mathrm{e}-5$ & $1.51 \mathrm{e}-5$ & $2.22 \mathrm{e}-5$ & $1.08 \mathrm{e}-5$ \\
\hline & $(4.04 \mathrm{e}-5)$ & $(6.36 \mathrm{e}-5)$ & $(8.16 \mathrm{e}-5)$ & $(2.94 \mathrm{e}-5)$ & $(9.35 \mathrm{e}-6)$ & $(2.17 \mathrm{e}-5)$ & $(2.14 \mathrm{e}-4)$ & $(1.88 \mathrm{e}-5)$ \\
\hline \multirow[t]{2}{*}{$\gamma$} & $4.45 \mathrm{e}+1$ & $3.84 \mathrm{e}+1$ & $2.73 \mathrm{e}+1$ & $3.28 \mathrm{e}+1$ & $1.91 \mathrm{e}+1$ & $6.53 \mathrm{e}+0$ & $1.19 \mathrm{e}+1$ & $3.26 \mathrm{e}+0$ \\
\hline & $(1.70 \mathrm{e}-2)$ & $(6.11 \mathrm{e}-3)$ & $(1.14 \mathrm{e}-2)$ & $(1.22 \mathrm{e}-2)$ & $(1.61 \mathrm{e}-2)$ & $(1.85 \mathrm{e}-1)$ & $(8.07 \mathrm{e}-2)$ & $(2.45 \mathrm{e}-2)$ \\
\hline \multirow[t]{2}{*}{$\lambda$} & $1.72 \mathrm{e}+0$ & $1.37 \mathrm{e}+1$ & $3.13 \mathrm{e}+0$ & $1.01 \mathrm{e}+1$ & $1.61 \mathrm{e}+0$ & $5.61 \mathrm{e}+0$ & $1.78 \mathrm{e}+0$ & $6.13 \mathrm{e}+0$ \\
\hline & $(1.39 \mathrm{e}-2)$ & $(1.05 \mathrm{e}-2)$ & $(2.09 \mathrm{e}-2)$ & $(7.59 \mathrm{e}-3)$ & $(7.22 \mathrm{e}-3)$ & $(1.96 \mathrm{e}-1)$ & $(6.33 \mathrm{e}-2)$ & $(7.86 \mathrm{e}-3)$ \\
\hline \multirow[t]{2}{*}{$\omega$} & $7.57 \mathrm{e}-6$ & $6.49 \mathrm{e}-6$ & $1.21 \mathrm{e}-5$ & $3.49 \mathrm{e}-6$ & $1.99 \mathrm{e}-6$ & $1.51 \mathrm{e}-7$ & $6.46 \mathrm{e}-5$ & $4.79 \mathrm{e}-7$ \\
\hline & $(9.64 \mathrm{e}-5)$ & $(1.90 \mathrm{e}-5)$ & $(1.74 \mathrm{e}-5)$ & $(2.52 \mathrm{e}-5)$ & $(6.53 \mathrm{e}-5)$ & $(4.33 \mathrm{e}-5)$ & $(1.92 \mathrm{e}-4)$ & $(3.25 \mathrm{e}-5)$ \\
\hline \multirow[t]{2}{*}{$\mu$} & $1.07 \mathrm{e}-3$ & $7.18 \mathrm{e}-4$ & $1.32 \mathrm{e}-3$ & $4.73 \mathrm{e}-4$ & $1.48 \mathrm{e}-3$ & $5.37 \mathrm{e}-4$ & $6.51 \mathrm{e}-4$ & $1.35 \mathrm{e}-4$ \\
\hline & $(1.29 \mathrm{e}-4)$ & $(6.74 \mathrm{e}-5)$ & $(3.76 \mathrm{e}-5)$ & $(5.26 \mathrm{e}-5)$ & $(5.00 \mathrm{e}-4)$ & $(1.45 \mathrm{e}-4)$ & $(1.32 \mathrm{e}-4)$ & $(3.38 \mathrm{e}-5)$ \\
\hline$L$ & $2.49 \mathrm{e}+3$ & $3.77 \mathrm{e}+3$ & $2.50 \mathrm{e}+3$ & $3.20 \mathrm{e}+3$ & $2.10 \mathrm{e}+3$ & $2.88 \mathrm{e}+3$ & $2.04 \mathrm{e}+3$ & $2.84 \mathrm{e}+3$ \\
\hline
\end{tabular}


Table 4: Box-Pierce and Ljung-Box statistics for tests of independence of residuals of the M-GARCH models for the marginal distributions. For each series, the statistic is computed for different numbers of lags $(1,4,6$, and 12$) .{ }^{*}$ and ${ }^{* *}$ means that we cannot reject independence at the 1 and 5 percent levels respectively

\begin{tabular}{|c|c|c|c|c|c|c|c|c|}
\hline & \multicolumn{2}{|c|}{$\overline{\mathrm{US}}$} & \multicolumn{2}{|c|}{$\overline{\mathrm{CA}}$} & \multicolumn{2}{|c|}{$\overline{\overline{F R}}$} & \multicolumn{2}{|c|}{$\overline{\overline{\mathrm{DE}}}$} \\
\hline & Equity & Bond & Equity & Bond & Equity & Bond & Equity & Bond \\
\hline \multicolumn{9}{|l|}{ Box-Pierce } \\
\hline 12 lags & $23.26^{*}$ & $18.57^{* *}$ & $14.42^{* *}$ & $9.27^{* *}$ & $10.93^{* *}$ & $9.88^{* *}$ & $8.64^{* *}$ & $12.19^{* *}$ \\
\hline 6 lags & $14.85^{*}$ & $12.19^{* *}$ & $10.26^{* *}$ & $7.17^{* *}$ & $10.70^{* *}$ & $5.06^{* *}$ & $4.55^{* *}$ & $8.85^{* *}$ \\
\hline 4 lags & $8.73^{* *}$ & $10.49^{*}$ & $9.02^{* *}$ & $6.34^{* *}$ & $7.00 * *$ & $3.7099 * *$ & $3.39^{* *}$ & $6.36^{* *}$ \\
\hline $1 \mathrm{lag}$ & $5.36^{*}$ & $0.01^{* *}$ & $3.71^{* *}$ & $0.45^{* *}$ & $6.11^{*}$ & $1.33^{* *}$ & $3.18^{* *}$ & $2.78^{* *}$ \\
\hline \multicolumn{9}{|l|}{ Ljung-Box } \\
\hline 12 lags & $23.43^{*}$ & $18.71^{* *}$ & $14.51^{* *}$ & $9.32^{* *}$ & $10.98^{* *}$ & $9.97 * *$ & $8.71^{* *}$ & $12.28^{* *}$ \\
\hline 6 lags & $14.93^{*}$ & $12.25^{* *}$ & $10.31^{* *}$ & $7.20^{* *}$ & $10.74^{* *}$ & $5.09 * *$ & $4.57^{* *}$ & $8.90^{* *}$ \\
\hline 4 lags & $8.76^{* *}$ & $10.55^{*}$ & $9.05^{* *}$ & $6.37^{* *}$ & $7.02^{* *}$ & $3.7248^{* *}$ & $3.40^{* *}$ & $6.38^{* *}$ \\
\hline $1 \mathrm{lag}$ & $5.37^{*}$ & $0.01 * *$ & $3.72^{* *}$ & $0.45^{* *}$ & $6.13^{*}$ & $1.33^{* *}$ & $3.19^{* *}$ & $2.79^{* *}$ \\
\hline
\end{tabular}


Table 5: Dependence structure between the United States and Canada in equity and bond markets. Correlation coefficients are reported for the normal regime, while tail dependence coefficients describe the asymmetric regime. The tail dependence coefficient is obtained as the product of parameter $\tau$ and the respective weight $\pi$ for cross-asset dependence and $1-\pi$ for cross-country dependence. Standard deviations are reported between parentheses for all parameters estimated directly from the model. The last raw reports the diagonal elements of the transition probability matrix.

\begin{tabular}{|c|c|c|c|c|c|}
\hline \multicolumn{6}{|c|}{ "Cross-Country (US-CA) Dependence } \\
\hline \multirow{2}{*}{\multicolumn{3}{|c|}{$\begin{array}{c}\text { Normal Regime } \\
\text { Correlation Coefficient }\end{array}$}} & \multirow{2}{*}{\multicolumn{3}{|c|}{$\begin{array}{c}\text { Asymmetric Regime } \\
\text { Tail Dependence Coefficient }\end{array}$}} \\
\hline & & & & & \\
\hline & & & & $\tau$ & $\operatorname{TDC}((1-\pi) \tau)$ \\
\hline \multirow{2}{*}{\multicolumn{2}{|c|}{ US Equity - CA Equity }} & 0.8739 & & 0.9100 & 0.7917 \\
\hline & & $(0.1560)$ & & $(0.0185)$ & \\
\hline \multirow{3}{*}{\multicolumn{2}{|c|}{ US Bond - CA Bond }} & 0.3870 & & 0.6234 & 0.5424 \\
\hline & & $(0.0831)$ & & $(0.0124)$ & \\
\hline & & & $1-\pi$ & 0.6897 & \\
\hline \multicolumn{6}{|c|}{ Cross-Asset (Equity-Bond) Dependence } \\
\hline \multirow{2}{*}{\multicolumn{3}{|c|}{$\begin{array}{c}\text { Normal Regime } \\
\text { Correlation Coefficient }\end{array}$}} & \multirow{2}{*}{\multicolumn{3}{|c|}{$\begin{array}{c}\text { Asymmetric Regime } \\
\text { Tail Dependence Coefficient }\end{array}$}} \\
\hline & & & & & \\
\hline \multirow{3}{*}{ US Equity } & US Bond & CA Bond & \multirow{3}{*}{ US Equity - US Bond } & $\tau$ & $\operatorname{TDC}(\pi \tau)$ \\
\hline & -0.1101 & 0.1234 & & 0.1300 & 0.0169 \\
\hline & $(0.0416)$ & $(0.0312)$ & & $(0.041)$ & \\
\hline \multirow[t]{7}{*}{ CA Equity } & -0.0812 & 0.4085 & CA Equity - CA Bond & 0.1385 & 0.0180 \\
\hline & $(0.0207)$ & $(0.0103)$ & & $(0.0145)$ & \\
\hline & & & $\pi$ & 0.3102 & \\
\hline & & & & $(0.0207)$ & \\
\hline & \multicolumn{4}{|c|}{ Parameters of transitional probability matrix } & \\
\hline & $P$ & 0.9020 & $Q$ & 0.9586 & \\
\hline & & $(0.0207)$ & & $(0.0206)$ & \\
\hline
\end{tabular}


Table 6: Dependence structure between France and Germany in equity and bond markets. Correlation coefficients are reported for the normal regime, while tail dependence coefficients describe the asymmetric regime. The tail dependence coefficient is obtained as the product of parameter $\tau$ and the respective weight $\pi$ for cross-asset dependence and 1- $\pi$ for cross-country dependence. Standard deviations are reported between parentheses for all parameters estimated directly from the model. The last raw reports the diagonal elements of the transition probability matrix.

\begin{tabular}{|c|c|c|c|c|c|}
\hline \multicolumn{6}{|c|}{ ClCross-Country (FR-DE) Dependence } \\
\hline \multirow{2}{*}{\multicolumn{3}{|c|}{$\begin{array}{c}\text { Normal Regime } \\
\text { Correlation Coefficient }\end{array}$}} & \multirow{2}{*}{\multicolumn{3}{|c|}{$\begin{array}{c}\text { Asymmetric Regime } \\
\text { Tail Dependence Coefficient }\end{array}$}} \\
\hline & & & & & \\
\hline & & & & $\tau$ & $\mathrm{TDC}((1-\pi) \tau)$ \\
\hline \multirow{2}{*}{\multicolumn{2}{|c|}{ FR Equity - DE Equity }} & 0.9083 & & 0.9554 & 0.7787 \\
\hline & & $(0.0267)$ & & $(0.0603)$ & \\
\hline \multirow{3}{*}{\multicolumn{2}{|c|}{ FR Bond - DE Bond }} & 0.9901 & & 0.8261 & 0.6733 \\
\hline & & $(0.058)$ & & $(0.027)$ & \\
\hline & & & $1-\pi$ & 0.8151 & \\
\hline \multicolumn{6}{|c|}{ Cross-Asset (Equity-Bond) Dependence } \\
\hline \multirow{2}{*}{\multicolumn{3}{|c|}{$\begin{array}{c}\text { Normal Regime } \\
\text { Correlation Coefficient }\end{array}$}} & \multirow{2}{*}{\multicolumn{3}{|c|}{$\begin{array}{c}\text { Asymmetric Regime } \\
\text { Tail Dependence Coefficient }\end{array}$}} \\
\hline & & & & & \\
\hline \multirow{3}{*}{ FR Equity } & FR Bond & DE Bond & \multirow{3}{*}{ FR Equity - FR Bond } & $\tau$ & $\mathrm{TDC}(\pi \tau)$ \\
\hline & 0.1893 & 0.2023 & & 0.0923 & 0.0171 \\
\hline & $(0.0170)$ & $(0.0129)$ & & $(0.028)$ & \\
\hline \multirow[t]{7}{*}{ DE Equity } & 0.1175 & 0.1294 & DE Equity - DE Bond & 0.0969 & 0.0179 \\
\hline & $(0.0214)$ & $(0.030)$ & & $(0.029)$ & \\
\hline & & & $\pi$ & 0.1849 & \\
\hline & & & & $(0.0294)$ & \\
\hline & \multicolumn{4}{|c|}{ Parameters of transitional probability matrix } & \\
\hline & $P$ & 0.8381 & $Q$ & 0.9373 & \\
\hline & & $(0.0270)$ & & $(0.0373)$ & \\
\hline
\end{tabular}


Table 7: Subperiod I (period before the introduction of the Euro currency: from January 01, 1985 to December 29, 1998 for a sample of 731 observations). Dependence structure between France and Germany in equity and bond markets. Correlation coefficients are reported for the normal regime, while tail dependence coefficients describe the asymmetric regime. The tail dependence coefficient is obtained as the product of parameter $\tau$ and the respective weight $\pi$ for cross-asset dependence and 1- $\pi$ for crosscountry dependence. Standard deviations are reported between parentheses for all parameters estimated directly from the model. The last raw reports the diagonal elements of the transition probability matrix.

\begin{tabular}{|c|c|c|c|c|c|}
\hline \multicolumn{6}{|c|}{ Cross-Country (FR-DE) Dependence } \\
\hline \multirow{2}{*}{\multicolumn{3}{|c|}{$\begin{array}{c}\text { Normal Regime } \\
\text { Correlation Coefficient }\end{array}$}} & \multirow{2}{*}{\multicolumn{3}{|c|}{$\begin{array}{c}\text { Asymmetric Regime } \\
\text { Tail Dependence Coefficient }\end{array}$}} \\
\hline & & & & & \\
\hline & & & & $\tau$ & $\operatorname{TDC}((1-\pi) \tau)$ \\
\hline \multirow{2}{*}{\multicolumn{2}{|c|}{ FR Equity - DE Equity }} & 0.6924 & & 0.9554 & 0.8663 \\
\hline & & $(0.0760)$ & & $(0.035)$ & \\
\hline \multirow{3}{*}{\multicolumn{2}{|c|}{ FR Bond - DE Bond }} & 0.9082 & & 0.8388 & 0.7606 \\
\hline & & $(0.038)$ & & $(0.061)$ & \\
\hline & & & $1-\pi$ & 0.9067 & \\
\hline \multicolumn{6}{|c|}{ Cross-Asset (Equity-Bond) Dependence } \\
\hline \multirow{2}{*}{\multicolumn{3}{|c|}{$\begin{array}{c}\text { Normal Regime } \\
\text { Correlation Coefficient }\end{array}$}} & \multirow{2}{*}{\multicolumn{3}{|c|}{$\begin{array}{c}\text { Asymmetric Regime } \\
\text { Tail Dependence Coefficient }\end{array}$}} \\
\hline & & & & & \\
\hline \multirow{3}{*}{ FR Equity } & FR Bond & DE Bond & \multirow{3}{*}{ FR Equity - FR Bond } & $\tau$ & $\operatorname{TDC}(\pi \tau)$ \\
\hline & 0.2091 & 0.1641 & & 0.1130 & 0.0105 \\
\hline & $(0.0123)$ & $(0.0151)$ & & $(0.021)$ & \\
\hline \multirow[t]{7}{*}{ DE Equity } & 0.1205 & 0.1519 & DE Equity - DE Bond & 0.0067 & 0.0006 \\
\hline & $(0.0106)$ & $(0.049)$ & & $(0.072)$ & \\
\hline & & & $\pi$ & 0.0933 & \\
\hline & & & & $(0.010)$ & \\
\hline & \multicolumn{4}{|c|}{ Parameters of transitional probability matrix } & \\
\hline & $P$ & 0.0651 & $Q$ & 0.9438 & \\
\hline & & $(0.0103)$ & & $(0.0102)$ & \\
\hline
\end{tabular}


Table 8: Subperiod II (period after the introduction of the Euro currency: from January 05, 1999 to December 21, 2004 for a sample of 313 observations). Dependence structure between France and Germany in equity and bond markets. Correlation coefficients are reported for the normal regime, while tail dependence coefficients describe the asymmetric regime. The tail dependence coefficient is obtained as the product of parameter $\tau$ and the respective weight $\pi$ for cross-asset dependence and 1- $\pi$ for crosscountry dependence. Standard deviations are reported between parentheses for all parameters estimated directly from the model. The last raw reports the diagonal elements of the transition probability matrix.

\begin{tabular}{|c|c|c|c|c|c|}
\hline \multicolumn{6}{|c|}{ Cross-Country (FR-DE) Dependence } \\
\hline \multirow{2}{*}{\multicolumn{3}{|c|}{$\begin{array}{c}\text { Normal Regime } \\
\text { Correlation Coefficient }\end{array}$}} & \multirow{2}{*}{\multicolumn{3}{|c|}{$\begin{array}{c}\text { Asymmetric Regime } \\
\text { Tail Dependence Coefficient }\end{array}$}} \\
\hline & & & & & \\
\hline & & & & $\tau$ & $\operatorname{TDC}((1-\pi) \tau)$ \\
\hline \multirow{2}{*}{\multicolumn{2}{|c|}{ FR Equity - DE Equity }} & 0.9426 & & 0.2598 & 0.2582 \\
\hline & & $(0.0950)$ & & $(0.0106)$ & \\
\hline \multirow{3}{*}{\multicolumn{2}{|c|}{ FR Bond - DE Bond }} & 0.9937 & & 0.8946 & 0.8892 \\
\hline & & $(0.0382)$ & & $(0.071)$ & \\
\hline & & & $1-\pi$ & 0.9940 & \\
\hline \multicolumn{6}{|c|}{ Cross-Asset (Equity-Bond) Dependence } \\
\hline \multirow{2}{*}{\multicolumn{3}{|c|}{$\begin{array}{c}\text { Normal Regime } \\
\text { Correlation Coefficient }\end{array}$}} & \multirow{2}{*}{\multicolumn{3}{|c|}{$\begin{array}{c}\text { Asymmetric Regime } \\
\text { Tail Dependence Coefficient }\end{array}$}} \\
\hline & & & & & \\
\hline \multirow{3}{*}{ FR Equity } & FR Bond & DE Bond & \multirow{3}{*}{ FR Equity - FR Bond } & $\tau$ & $\operatorname{TDC}(\pi \tau)$ \\
\hline & 0.2272 & 0.2350 & & 0.2249 & 0.0013 \\
\hline & $(0.0241)$ & $(0.0177)$ & & $(0.024)$ & \\
\hline \multirow[t]{7}{*}{ DE Equity } & 0.1516 & 0.1573 & DE Equity - DE Bond & 0.9760 & 0.0059 \\
\hline & $(0.0118)$ & $(0.059)$ & & $(0.082)$ & \\
\hline & & & $\pi$ & 0.0060 & \\
\hline & & & & $(0.012)$ & \\
\hline & \multicolumn{4}{|c|}{ Parameters of transitional probability matrix } & \\
\hline & $P$ & 0.9212 & $Q$ & 0.2274 & \\
\hline & & $(0.0118)$ & & $(0.0117)$ & \\
\hline
\end{tabular}


Table 9: Monte Carlo Tests of Asymmetric Dependence. $L R$ is the likelihood ratio statistic computed from the data. The $p$-value is obtained from 1000 Monte Carlo repetitions with size 1043 (equal to the sample size) each.

\begin{tabular}{ccc}
\hline \hline & US-Canada & France-Germany \\
\hline$L R$ & 0.0731 & 0.7889 \\
$p-$ value & 0.0090 & 0.0000 \\
\hline \hline
\end{tabular}

Table 10: Longin and Solnik (2001) likelihood ratio test for extreme dependence correlation equal to zero at different thresholds. We apply this test on data, the regime switching model of Ang and Chen (2002), and the rotated Gumbel copula. we estimate the RS model and rotated Gumbel copula model and use estimates to simulate 10000 Monte Carlo replications. We then perform the test on these replications.

\begin{tabular}{|c|c|c|c|c|c|c|}
\hline \multirow[b]{2}{*}{ Threshold } & \multicolumn{2}{|c|}{ RS Model } & \multicolumn{2}{|c|}{ Data } & \multicolumn{2}{|c|}{ Rotated Gumbel copula } \\
\hline & LR & p-value & LR & p-value & LR & p-value \\
\hline 0.10 & 0.7800 & 0.3771 & 1.5501 & 0.2131 & 0.4091 & 0.5224 \\
\hline 0.20 & 2.2650 & 0.1323 & 1.5550 & 0.2124 & 8.6980 & 0.0032 \\
\hline 0.30 & 16.7210 & 0.0000 & 8.0980 & 0.0044 & 14.4370 & 0.0001 \\
\hline 0.40 & 22.3550 & 0.0000 & 30.9550 & 0.0000 & 27.6261 & 0.0000 \\
\hline 0.60 & 15.5351 & 0.0001 & 285.1200 & 0.0000 & 258.9300 & 0.0000 \\
\hline 0.70 & 10.8120 & 0.0010 & 168.6500 & 0.0000 & 219.2812 & 0.0000 \\
\hline 0.80 & 7.2661 & 0.0070 & 69.1500 & 0.0000 & 71.2000 & 0.0000 \\
\hline 0.90 & 3.4170 & 0.0645 & 20.3500 & 0.0000 & 29.7101 & 0.0000 \\
\hline
\end{tabular}




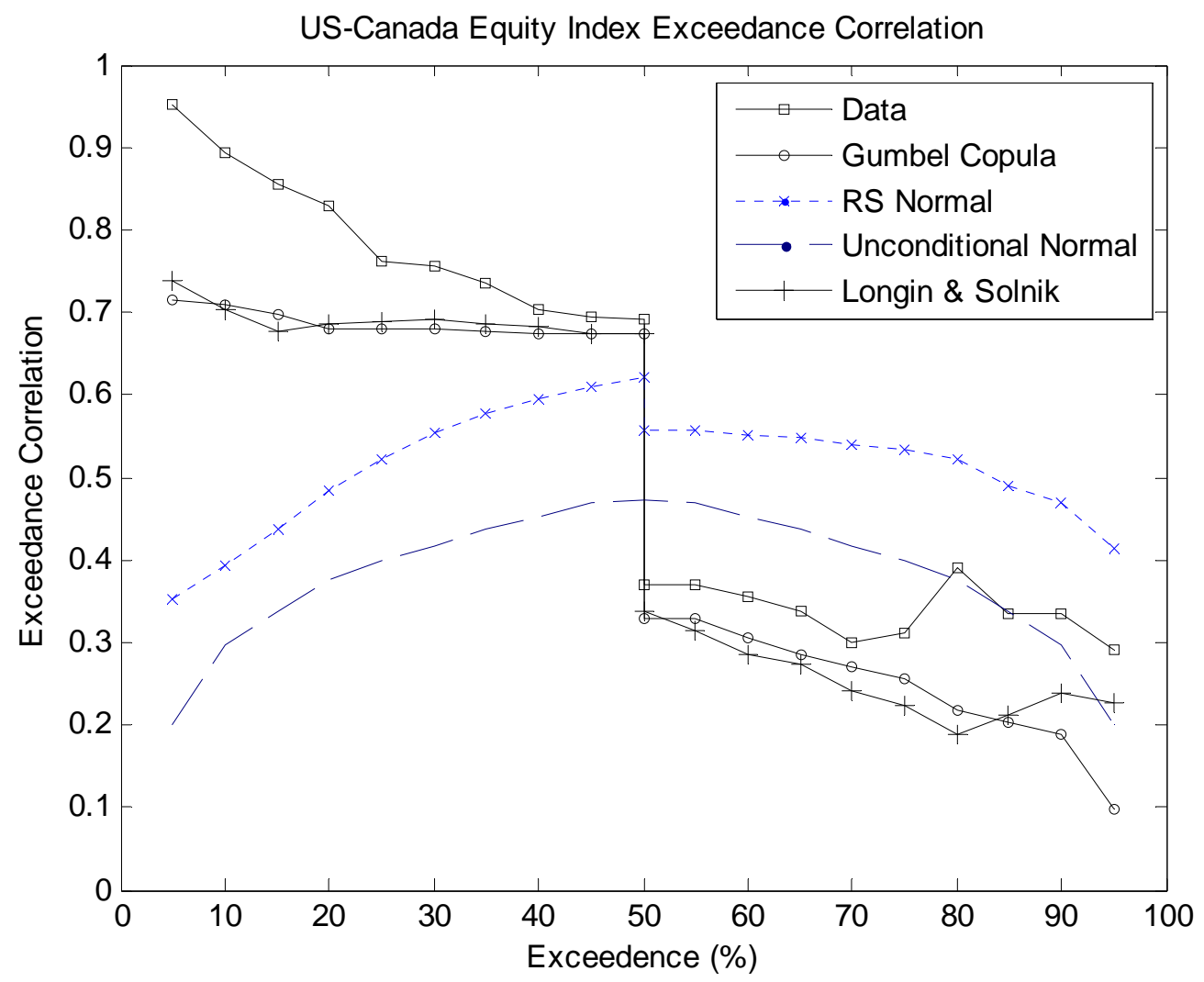

Figure 1: Calculates correlations from US-Canada equity returns data for different values of threshold $\theta$, which is normalized. For $\theta$ less than $50 \%$ the correlation is calculated for left tail and for $\theta$ greater than $50 \%$, the correlation is calculated for right tail. $\theta=80 \%$ means that we calculate the correlation conditional on $20 \%$ greatest observations for both U.S. and Canadian equity returns, and $\theta=10 \%$ means that we calculate the correlation conditional on $10 \%$ lowest observations for both U.S. and Canadian equity returns. Solid line represents the exceedance correlations calculated directly from data. For Rotated Gumbel Copula with Gaussian Margins (Gumbel Copula), Normal Regime Switching Distribution (RS Normal), and Normal Distribution (Unconditional Normal), we first estimate the model and use estimates to generate 50000 Monte Carlo simulations to calculate correlations. Longin \& Solnik exceedances correlations are obtained by Longin and Solnik (2001) estimation method. 


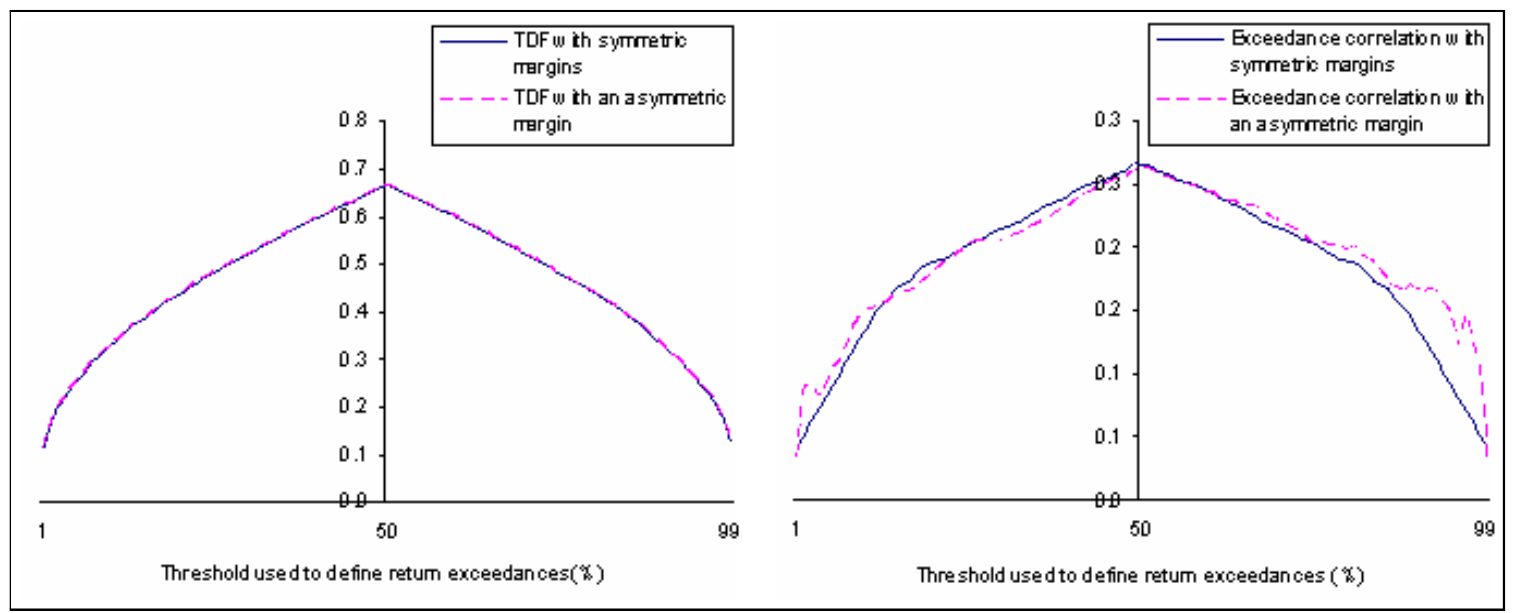

Figure 2: Effect of marginal distribution asymmetry on Tail Dependence function and Exceedance correlation: Firstly we simulate standard bivariate Gaussian distribution with correlation 0.5 and compute TDF and Exceedance correlation. Secondly, we create asymmetry in one marginal distribution by replacing the $N(0,1)$ by a mixture of $N(0,1)$ and $N(4,4)$ with equal weight.

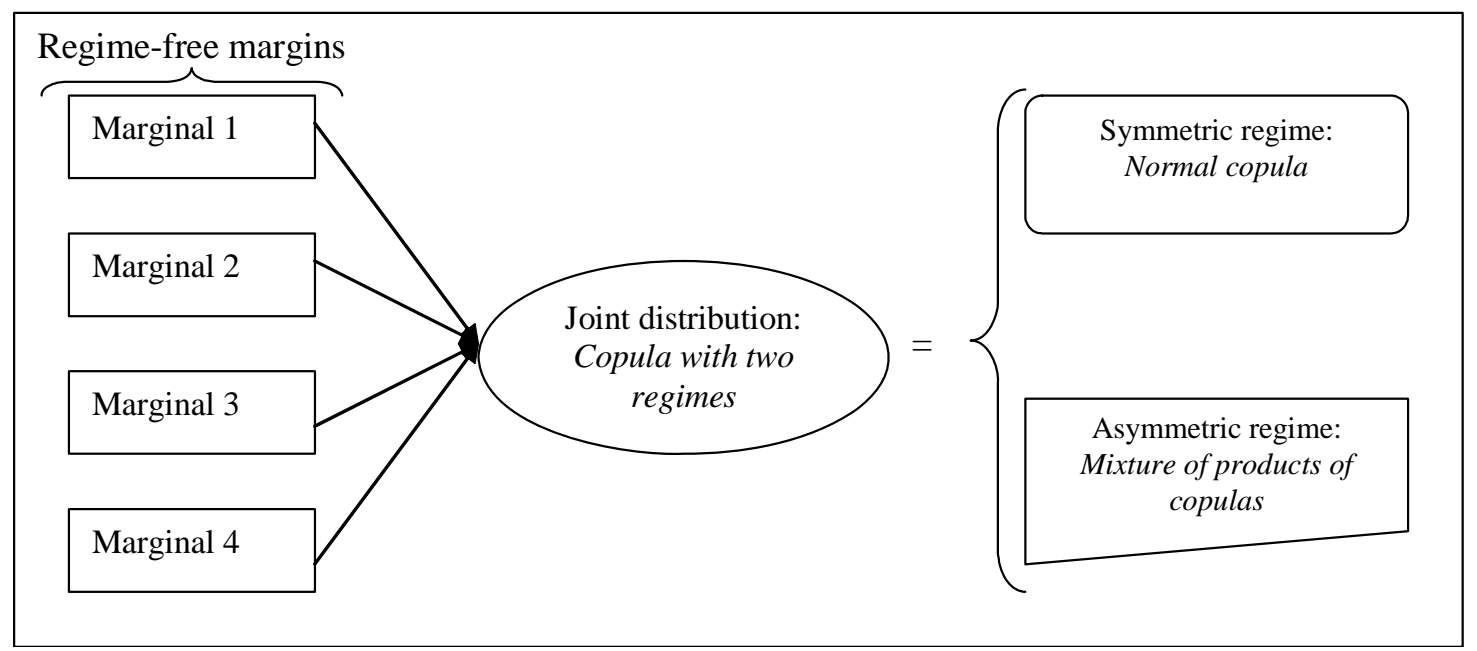

Figure 3: Model structure: Disentangling marginal distributions from the dependence structure with a two-regime copula, with one symmetric regime and one asymmetric regime. The marginal distributions are regime-free. 


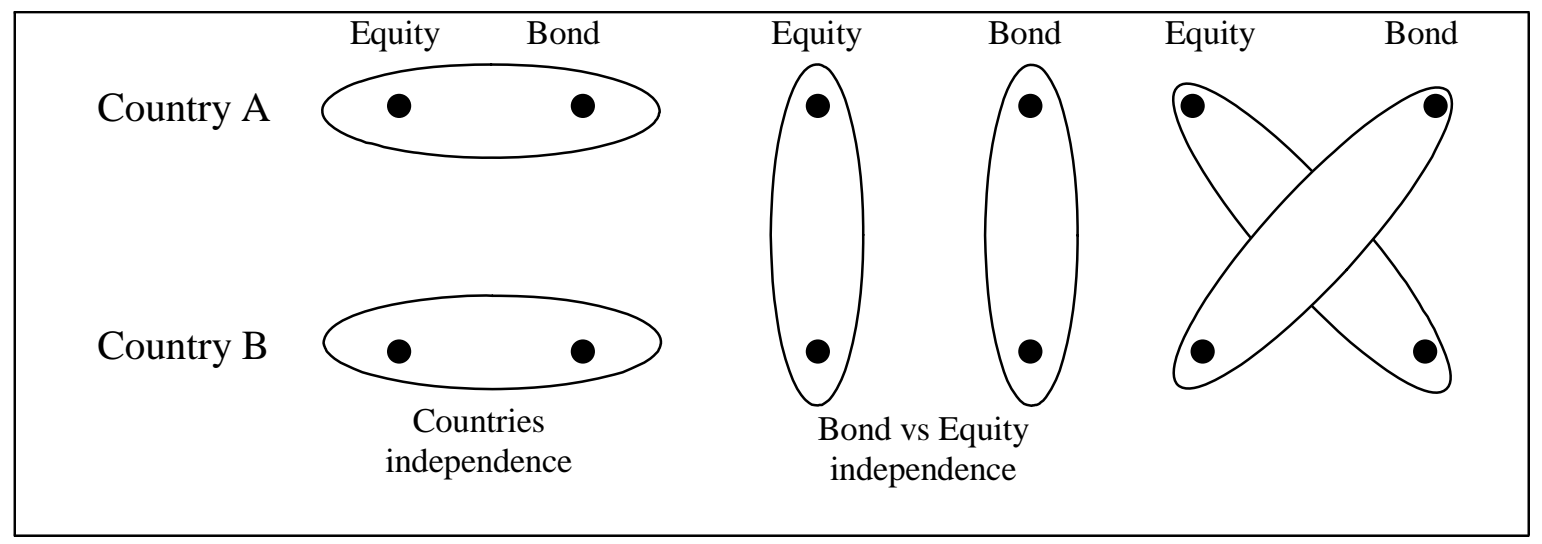

Figure 4: Illustration of the three components of asymmetric copula. Each component is the product of the two bivariate copulas representing the corresponding encircled couple of returns. 